\title{
أحوال اشور السياسية قبل العصر السرجونى
}

الباحثة/ زينب أحمد علي إبراهيم

$$
\text { الملخص: }
$$

يرجع قيام دولة الآشوريين إلى بداية الألف الثالث قبل الميلاد، وكانوا ينتمون إلى أصل

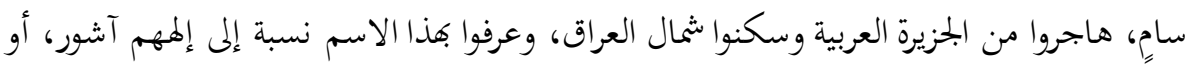

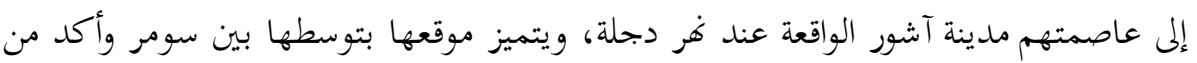

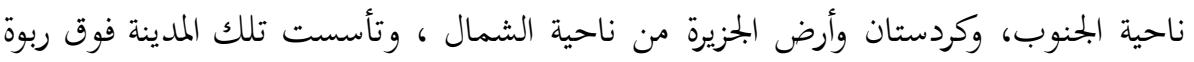

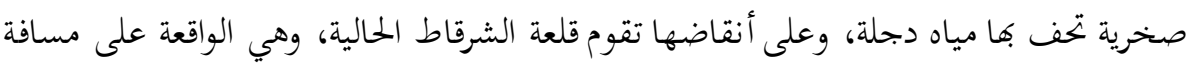

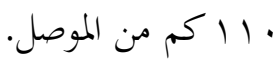

يتميز موقع بلاد آشور بطبيعته الجبلية المنحصر بين رقعة خصبة من الوديان والأغمار، والتي

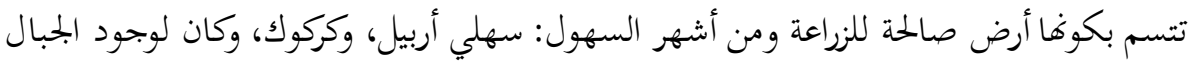

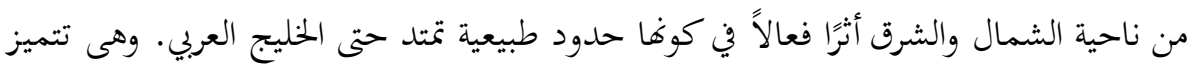
في ذلك عن حدودها السياسية الجنوبية والغربية الخالية من أية مرتفعات تحميها.

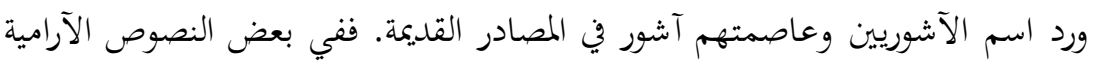
ورد بلفظة "أثور" و "أفور"، وكانت صياغة لفظة آشور عند السوماريين على هيئه "آ - اوسار"

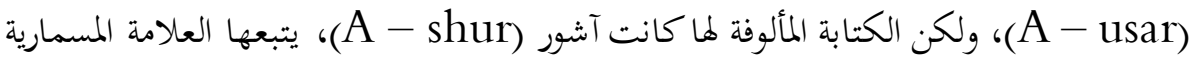
الدالة على الأمكنة "كي Ki"، بينما وردت صيغتها في النصوص الأكادية المكتشفة في مدينة "نوزي" بلفظة "كاسر Casur"، ومع مرور الوقت تحرف الاسم إلى آشور، وللتعبير عن بلاد

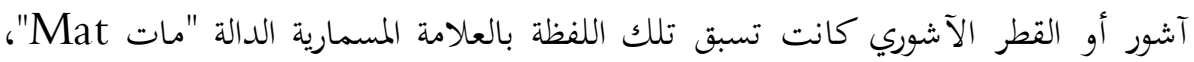

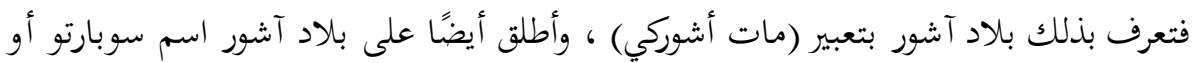

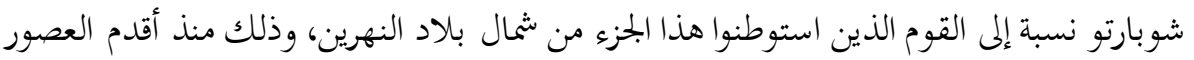

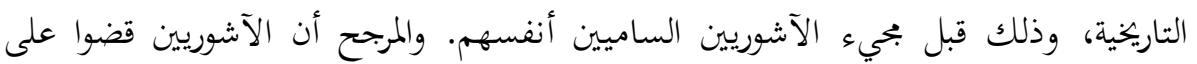

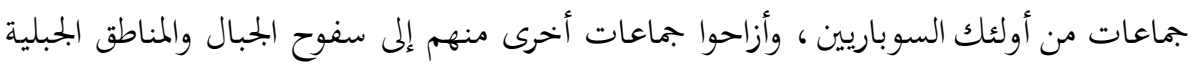

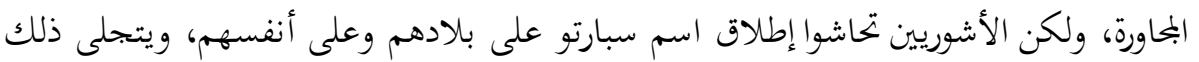

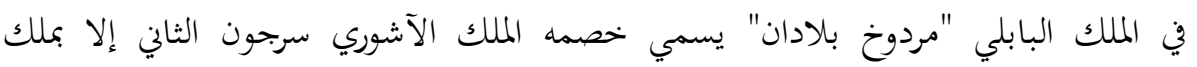


قامت آشور على أساس حربي عرف أهلها كيفية حماية حدودهم، فكانت كفيلة بردع

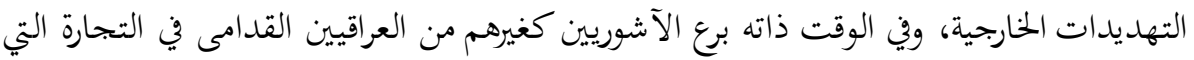
دون شك قد وثقت صلاكم بالشعوب الأخرى المحاورة فازدادوا بهذا قوة وثراء.

The establishment of the state of the Assyrians dates back to the beginning of the third millennium $\mathrm{BC}$, and they belonged to a sublime origin. They migrated from the Arabian Peninsula and inhabited northern Iraq. To the south, and Kurdistan and the land of the island from the north, and that city was established over a rocky hill surrounded by the waters of the Tigris, and on its ruins the current al-Sharqat castle, which is located at a distance of $110 \mathrm{~km}$ from Mosul, Assyria was established on a war basis, whose people knew how to protect their borders, so it was capable of deterring external threats, and at the same time the Assyrians excelled, like other ancient Iraqis, in trade that undoubtedly strengthened their ties with other neighboring peoples, thus increasing their strength and wealth.

\section{اولا : الحياه السياسية بآشور بعصريها القديم والوسيط}

تنقسم آشور عبر تاريخها القديم إلى ثلاثة عصور متميزة ومتتالية، تبدأ بالعصر الآشوري بعهيت

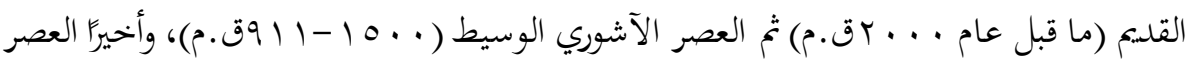

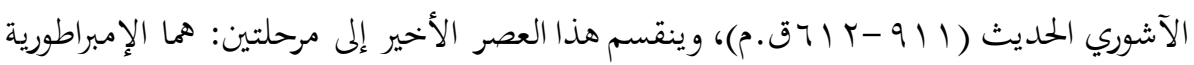

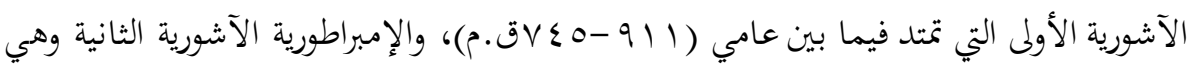

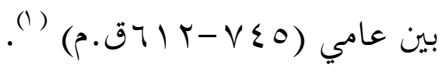

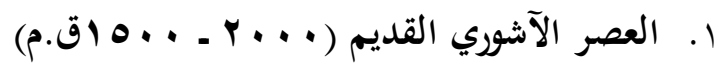

يبدأ هذا العصر مع ظهور الآشوريين على مسرح الأحداث في النصف الأول من

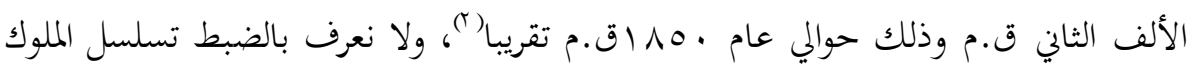


الذين حكموا في هذا العهد، على الرغم من وجود رقيم طيني يعود إلى القرن الثامن عشر ق.م

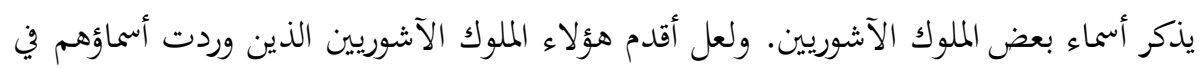

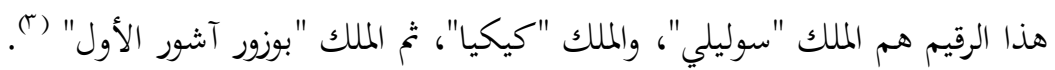

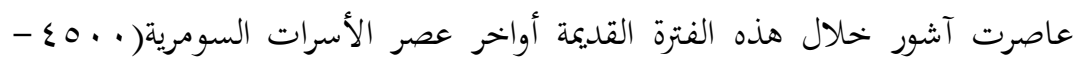

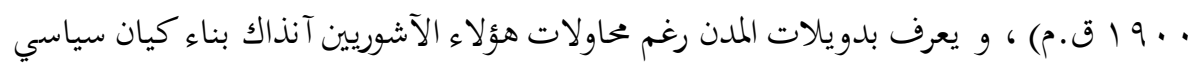

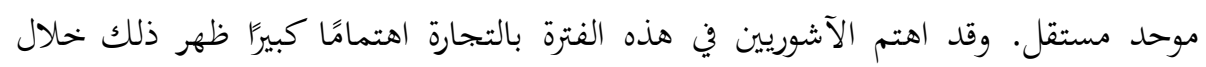

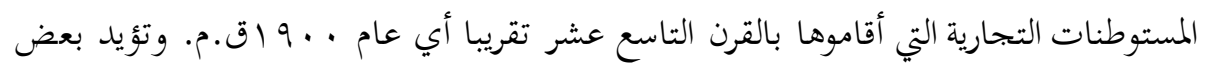

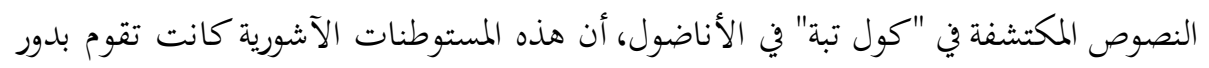

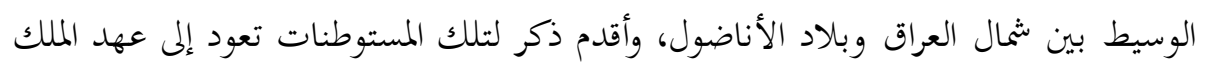

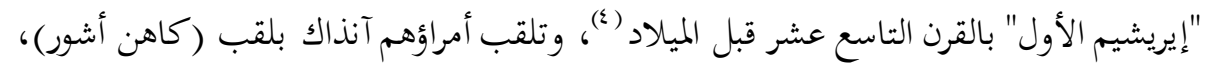

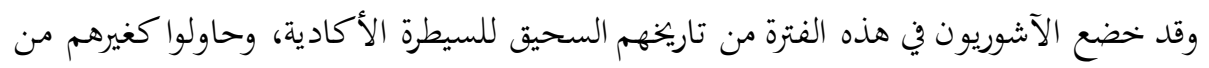

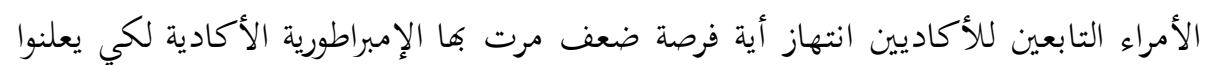

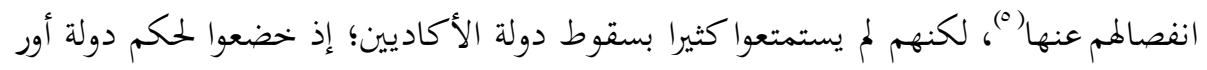

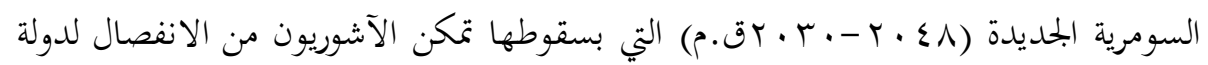

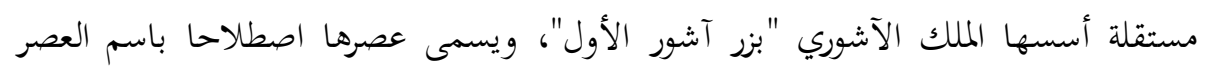
الآشوري القديم () عاصرت هذه الأسرة في بدايتها عصر دولتي إيسين ولارسا، ويذكر أن الملك "بزر" أعاد

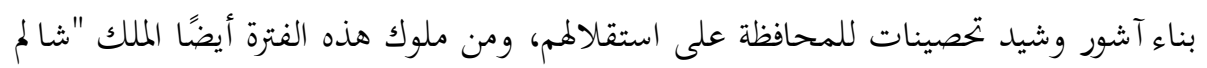

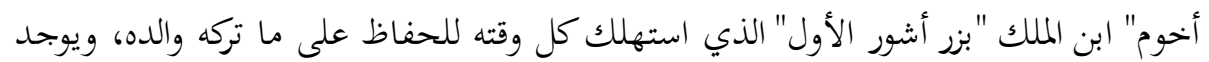

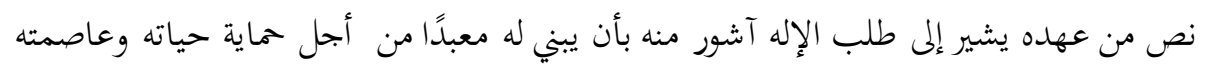
وذلك فيما نصه "من أجل حياته ومن أجل مدينته." (").

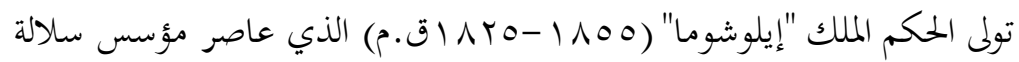

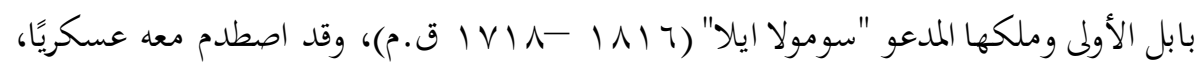

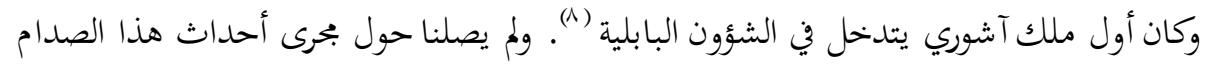

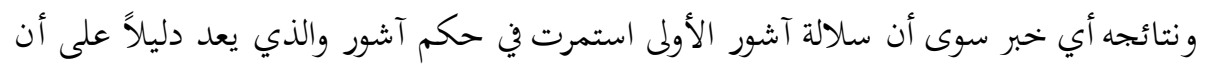

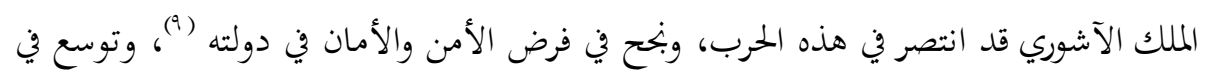

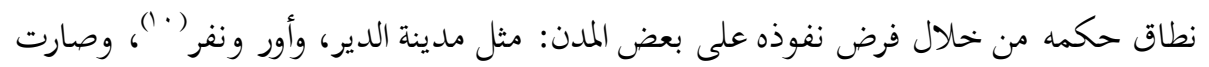


الدولة الآشورية في عهده أقوى وأوسع من ذي قبل؛ حيث امتد نفوذه جنوب مدينة الدير الواقعة

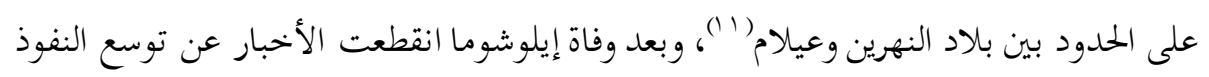
السياسي للآشوريين.

تعاقب على عرش آشور عدة ملوك تميز عصرهم بالضعف حتى تولى الملك "إيريشم

الأول" (ع اq ا - هبو اق.م) الذي في عهده ازدهرت التجارة إلى حد كبير بين آشور وآسيا

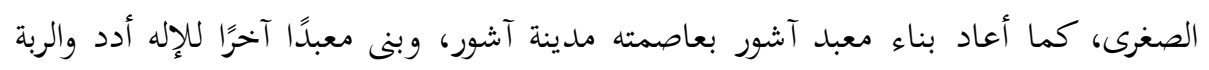

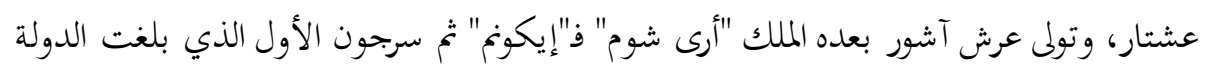

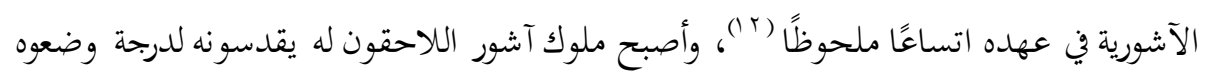
في مصاف الآلمة (r)" حدث ضعف في السلطة الحاكمة الآشورية في آخر عهد الملك سرجون ملكون الأول، وأصيبت بالارتباك في عهد كل من الملك "بوزور أشور الثاني" والملك "نارام سين" والملك "أرى شوم الثاني" لدرجة أن إحدى الدويلات، وهي محلكة إشنونة، تمكنت في فترة قصيرة فرض

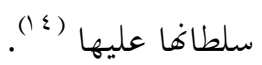

عادت آشور مرة أخرى إلى القوة والازدهار في هذا العصر القلدي، بعد أن

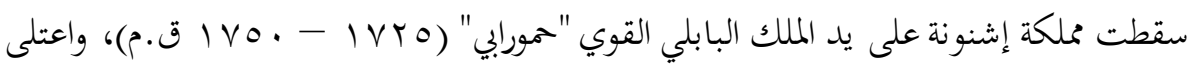

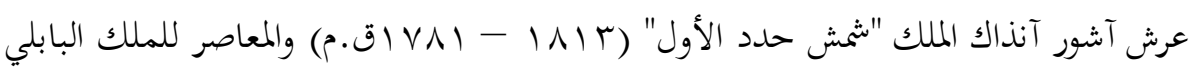
محورابي، الذي استولى على محلكة إشنونة، ووع اعتلاء الملك شمش حدد الأول انتعشت دولة

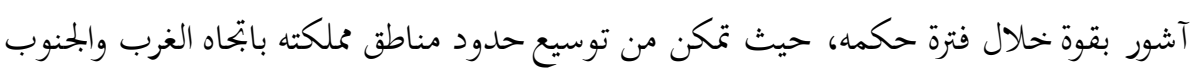
الغربي، وأخضع قسمًا من مناطق شمال سورية لسلطانه، واصطلم مع العائلة العمورية الحاكمة في

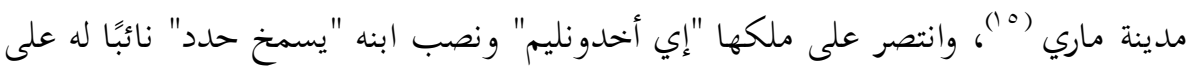
عرشها، وعين الابن الآخر "أشمي داكان" حاكما على إيكالتم (1 ().

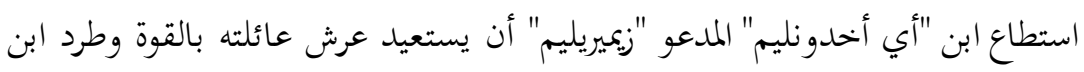

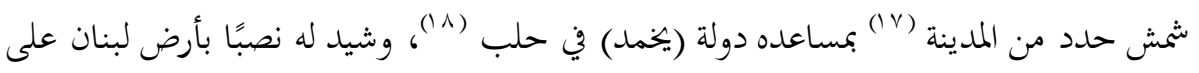
شاطئ البحر المتوسط. وتذكر أحد نصوصه أنه أقام مسلات على ساحل البحر المتوسط، وكان

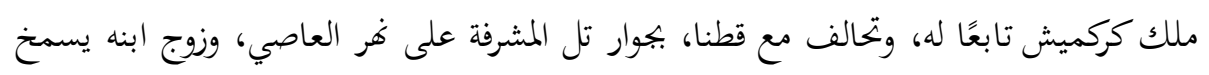
حدد بابنة ملك قطنا؛ لذا فقد امتدت قوته إلى شمال سورية، وفي الشرق حتى سفوح جبال زاجروس، ويصف شمش حدد الأول في أحد كتاباته أنه أذل بلاد دجلة والفرات، ويفتخر بنفسه

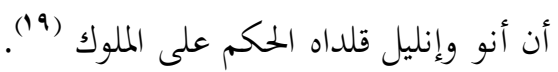


بدأت دولة آشور في الضعف والتدهور ليبدأ بعد ذلك عصر جديد لآشور وينتهي عصر

آشور القديم.

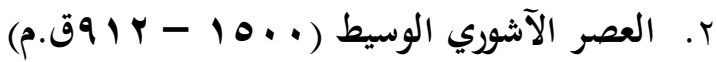

تطورت دولة آشور وقويت شوكتها خلال هذا العصر، ويبدأ بعهد الملك "بوزور آشور

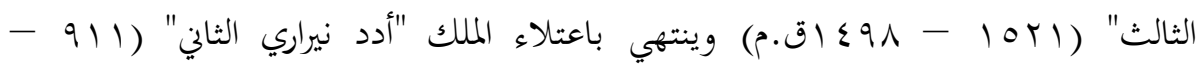

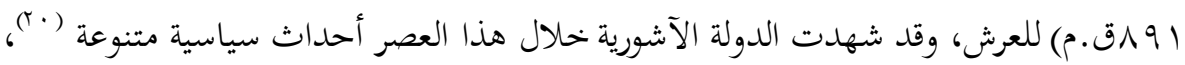
، تأثرت بعلاقاتا مع مختلف القوى الدولية آنذاك، وقد استهل ذلك بتخليصها من سطوة الملك البابلي القوي حمورابي، فعقب وفاته سقطت دولة بابل ،حيث طمع ملك الحيثيين ( (T) المدعو "مورشيلي الأول" في السيطرة عليها، وأرسل جيوشه إلى بلاد النهرين واستولى على بابل، ولكن.

نشبت ثورة عارمة ضد هذا الملك في عاصمته خاتوساسي (r) '). اضطر إلى سحب جيوشه من بلاد النهرين لمواجهة تلك الثورة، فتمكنت أقوام من سكان

جبال زاجروس من السيطرة على أرض بابل تدعى الكاشيين (rr)، وأمام ازدياد قوة الحيثيين والكاشيين اضطر الآشوريون للتقوقع داخل بلادهم بتنبًا للخوض في مواجهات عسكرية لا تساعدهم عليها إمكانياتم البشرية والمادية المحدودة آنذاك، وقد زاد الطين بلة أمام آشور؛ إذ ظهرت قوة دولة جديدة تعرف بالميتانية(؟) (تاـ ميتا)، وأصبح نفوذ تلك الدولة تمتد من شمال سورية حتى ساحل البحر المتوسط، واتخذت من مدينة "واشكاني" عاصمة لما وتمكن ملكها "شاوشتار" من تحديد دولة آشور واحتلال عاصمتها مدينة آشور نفسها وغبها وغبب معابدها، ولكن استقلت عنها آشور بعد أن منيت دولة ميتان بهزائم عديدة أمام الحيثيين (ب).

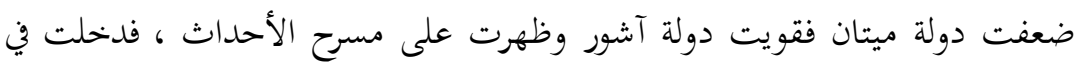

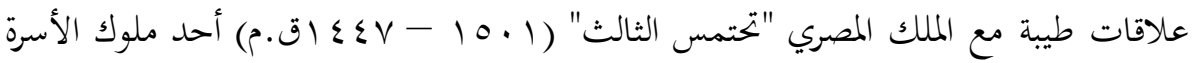

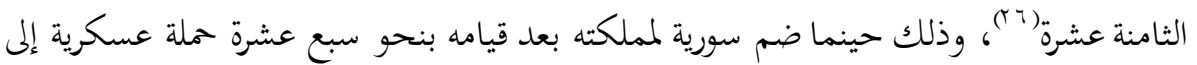
هناك، وأخذ يهدد دولة الميتانيين بقوة؛ مما جعل آشور يسارع لنيل وده حتى يقضي على عدوه اللدود في مملكة ميتان التي أصبحت آنذاك تعاني من مرحلة الضعف والاضطراب؛ مما جعل بعد

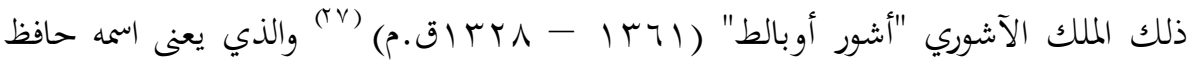
الحياة. ويعد الباحثون عصره عصر ازدهار شهدت فيه بلاد آشور هضة سياسية وحضارية، فاستطاع الانتصار على الملك الميتاني "ارتاتاما الثاني" في هاية سلسلة من الحروب المتواصلة، واستطاع القضاء على الدولة الميتانية وضمها إلى أملاكه واعترافها بالدولة الآشورية (^؟). 
خاضت آشور في العصر الوسيط صراعًا كبيرًا ضد دولة الكاشيين التي أسقطت مملكة

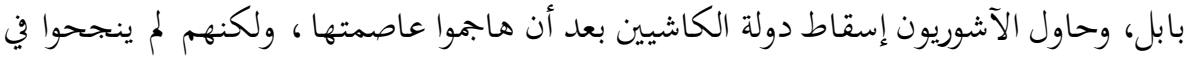

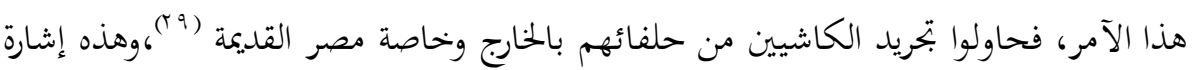

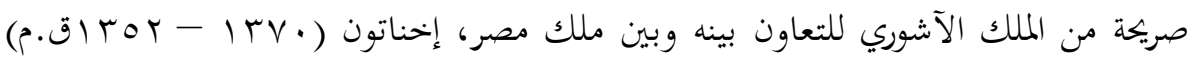

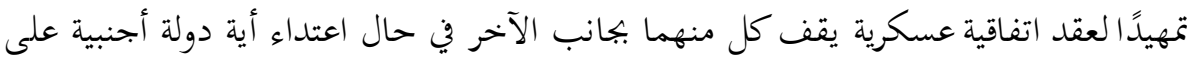

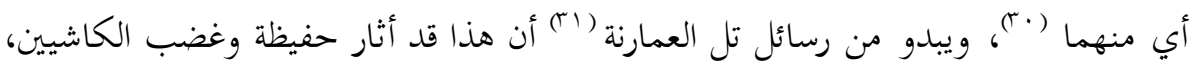

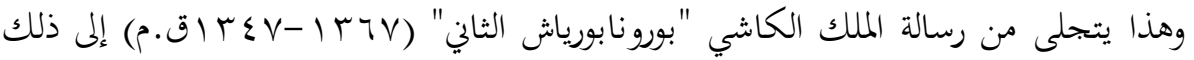
الملك المصري إخناتون يعاتبه على مراسلته لخصمه اللدود، ملك آشور، ولمقابلته الوفد الآشوري

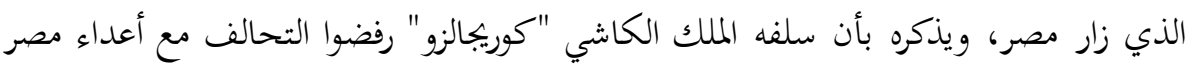

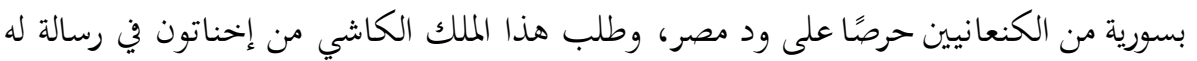

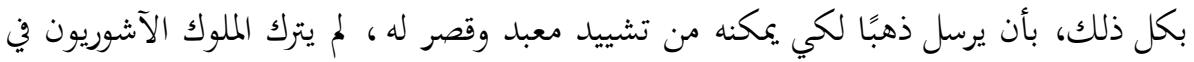

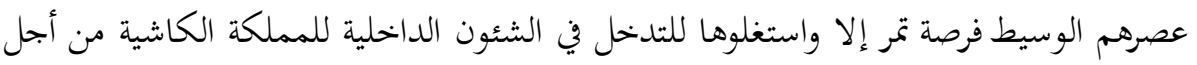

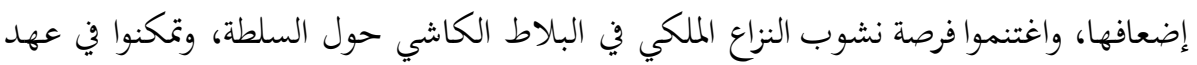

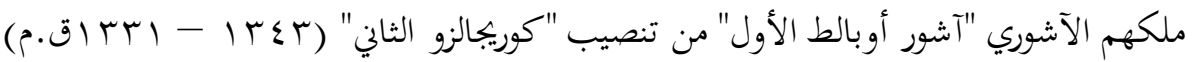
على عرش المملكة الكاشية (r).

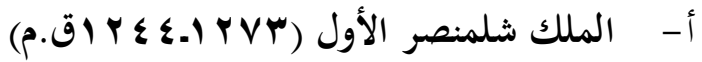

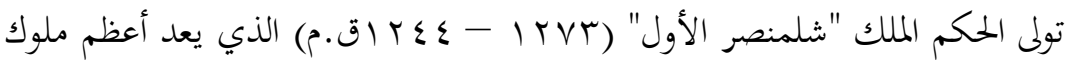

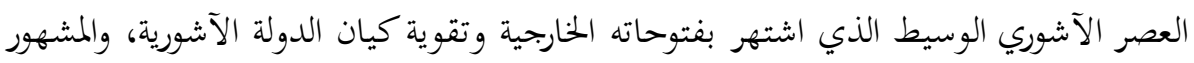

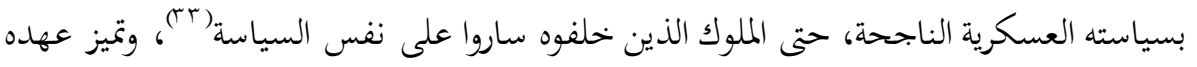

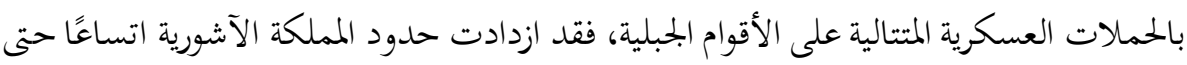

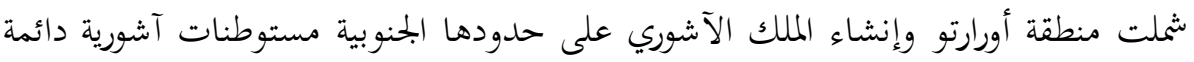

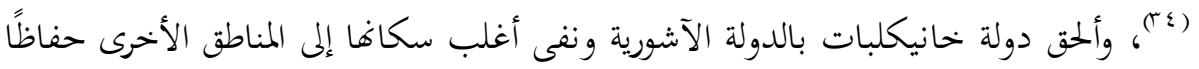

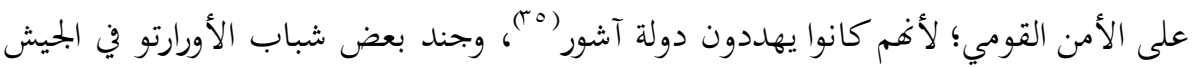

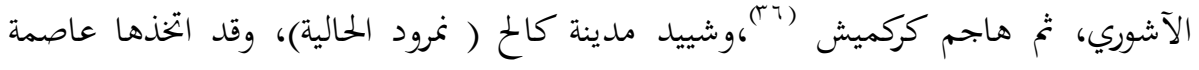

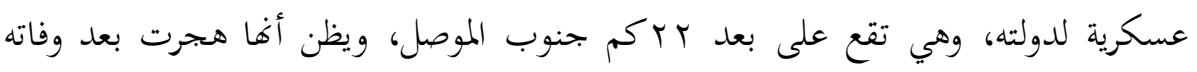

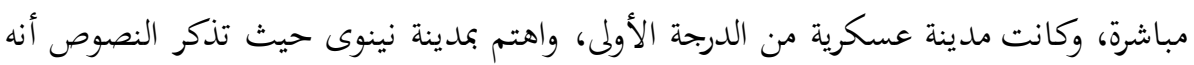


رمم معابدها، وازدهرت التجارة في عهده وخاصة مع بلاد نائيري في الأناضول ووضع حاميات

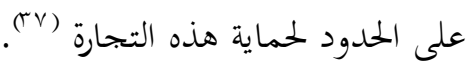

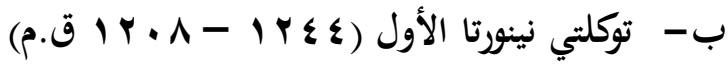

تمكن الآشوريون من إسقاط دولة الكاشيين في عهد توكلتي نينورتا الأول خليفة شلمناصر

حينما قام الملك الآشوري توكلتي الأول باقتحام مدينة بابل وهزم ملكها الكاشي

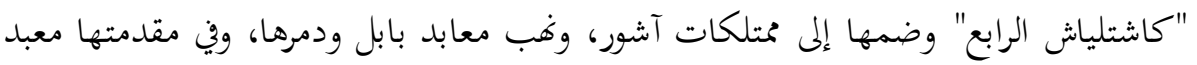

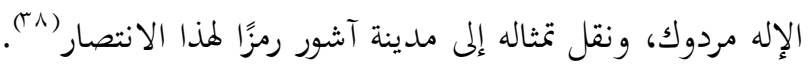

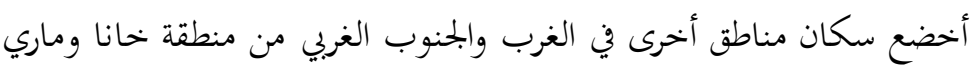

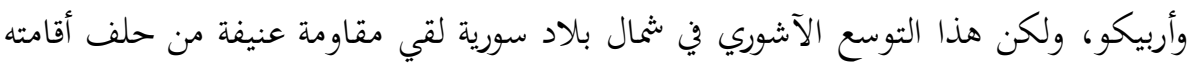

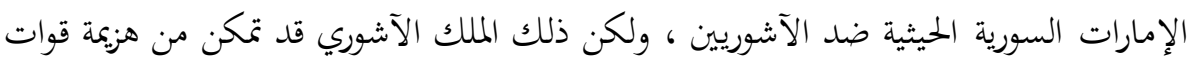

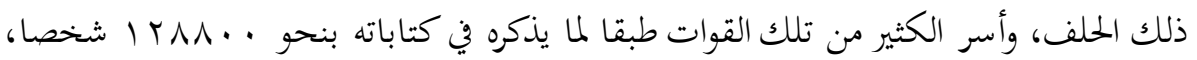

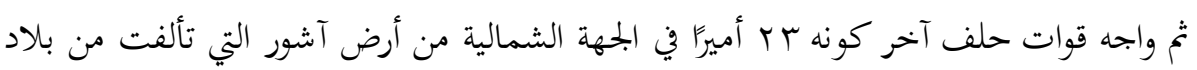

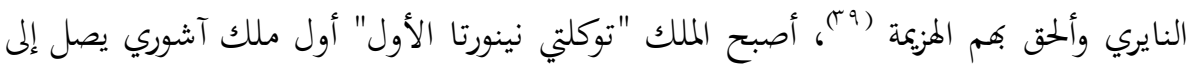

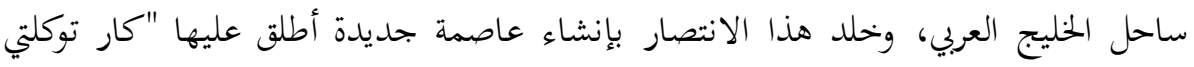

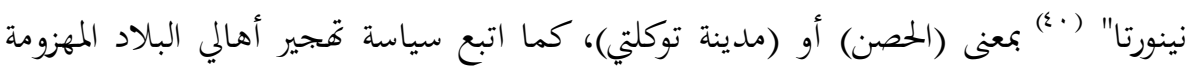

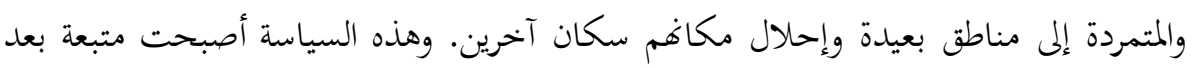

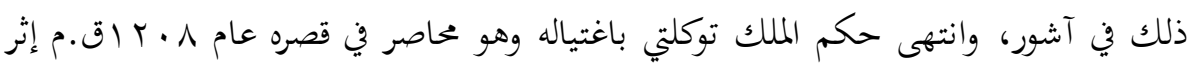

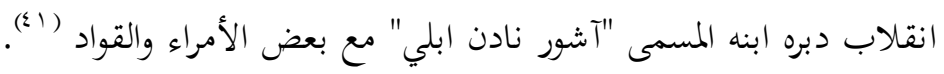

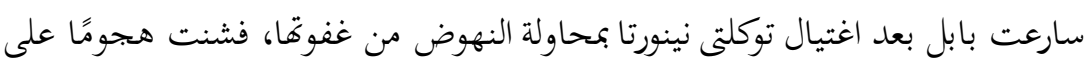

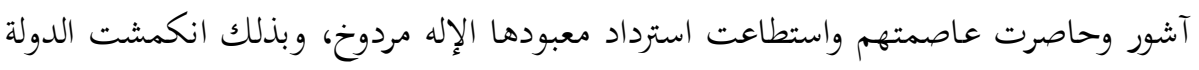

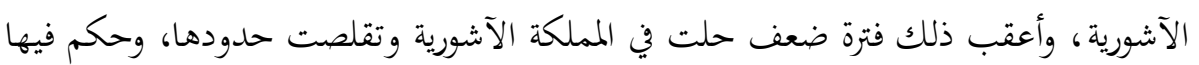

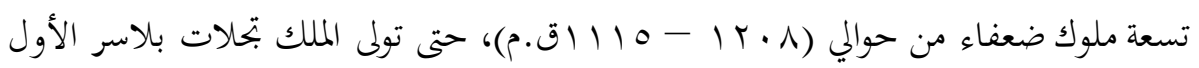

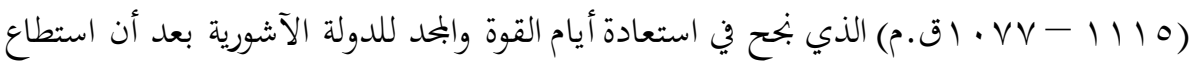

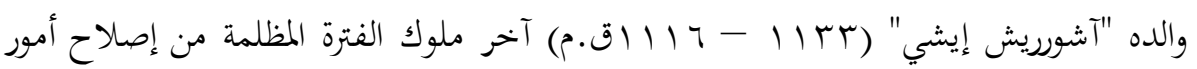
بلاده، ووقف الأخطار التي تمددها من الشمال والغرب والجنوب؛ حيث تصدى لقبائل الفرنج

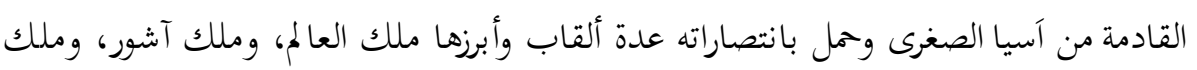




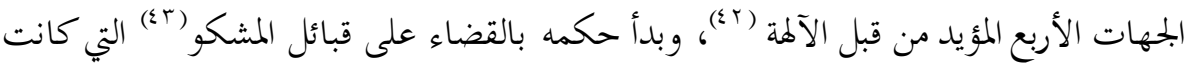
تتدفق لبلاده بمجموعات كبيرة من آسيا الصغرى، كما تصدى للقبائل الآرامية في سورية، التي

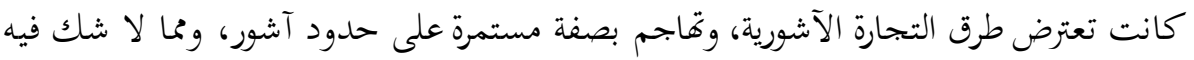

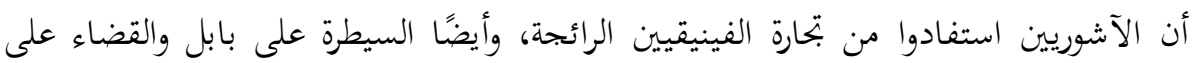

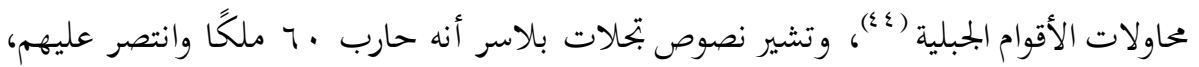

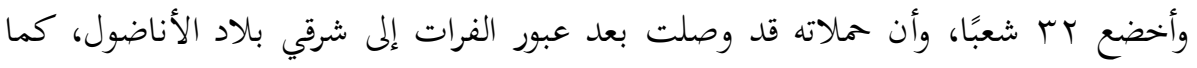

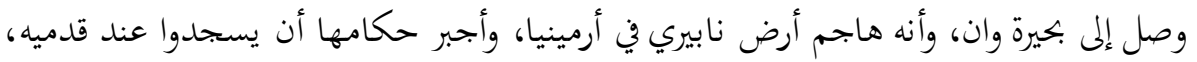

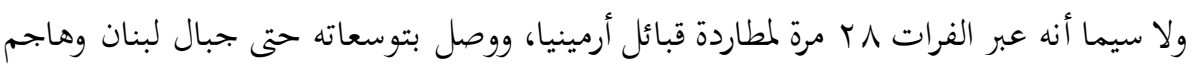

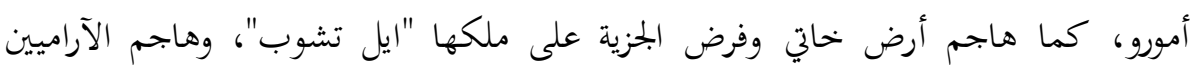

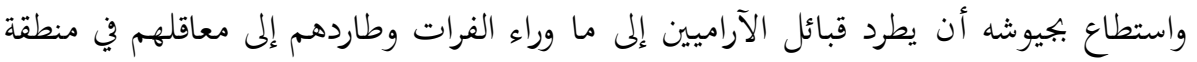

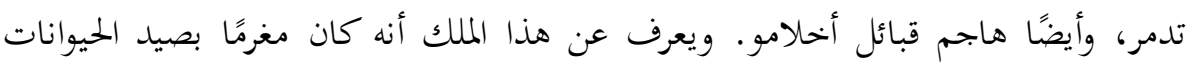

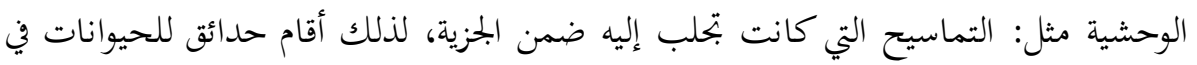

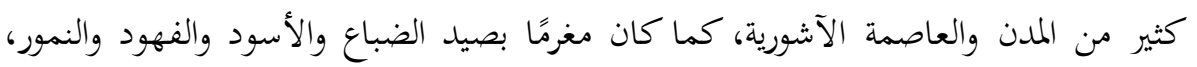

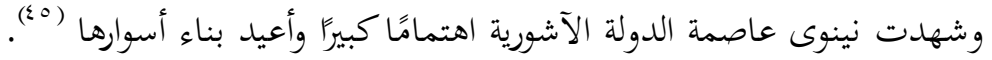

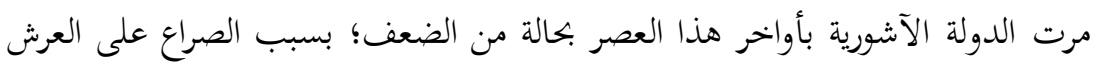

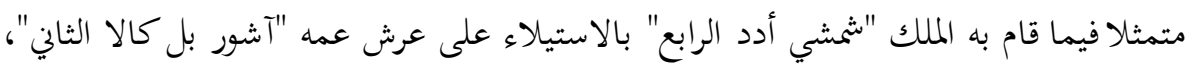

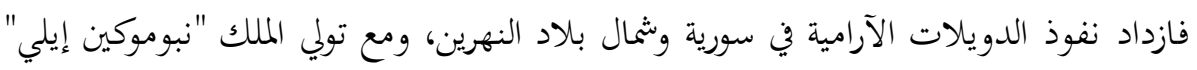

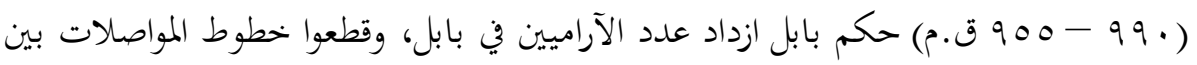

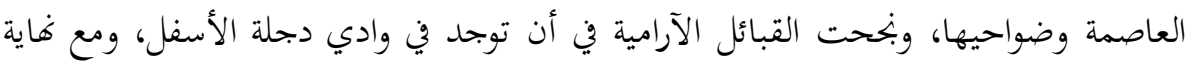

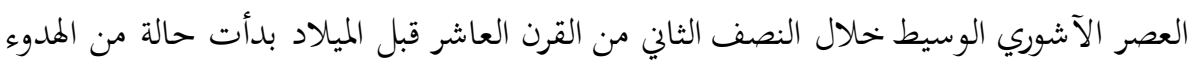

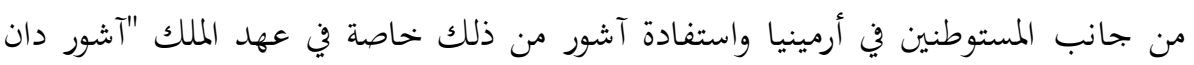

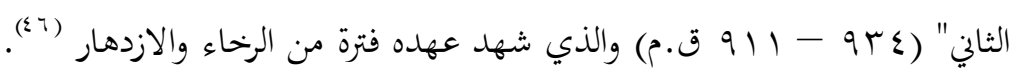

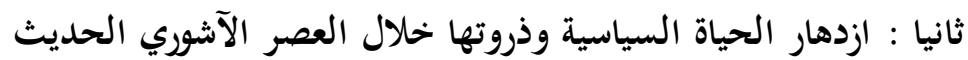

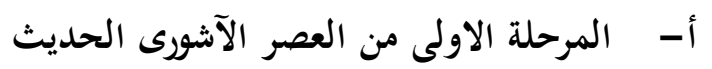

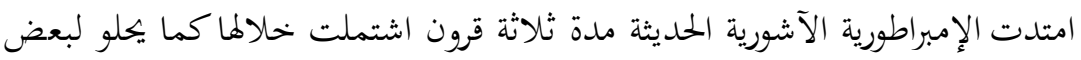

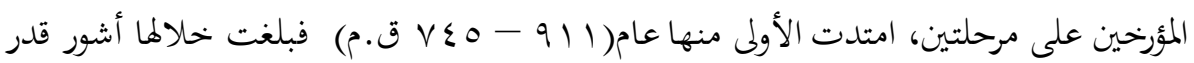

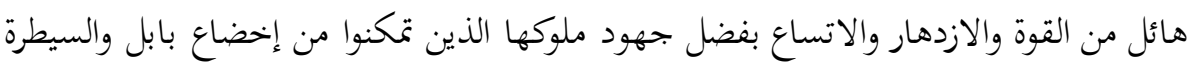


على المناطق الجبلية بالشمال والشرق من بلاد النهرين، ومد نفوذهم كذلك إلى الأراضي السورية،

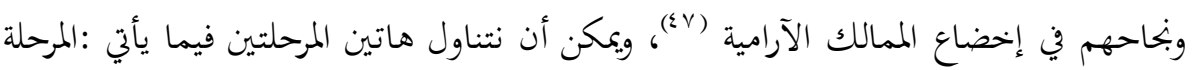

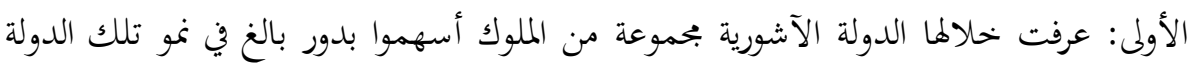
حتى تمكنت في المرحلة الثانية من السيطرة على معظم الشرق الأدنى القديم، وأهم ملوك المرحلة الاولى هم:

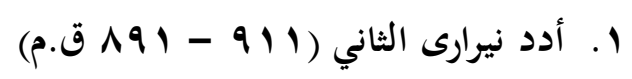

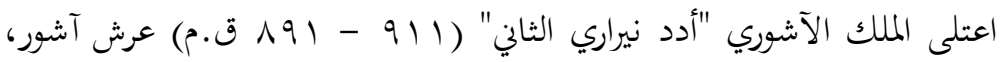

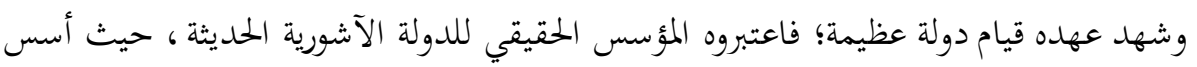

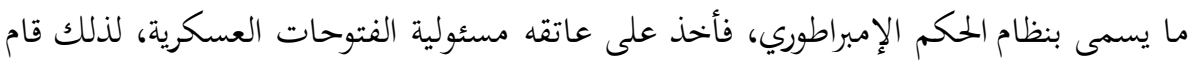

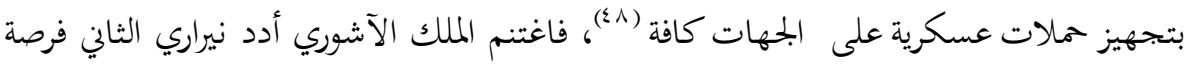

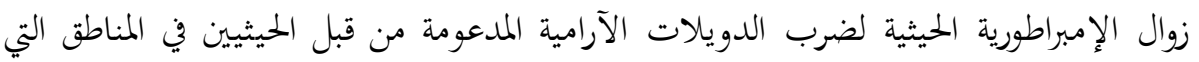

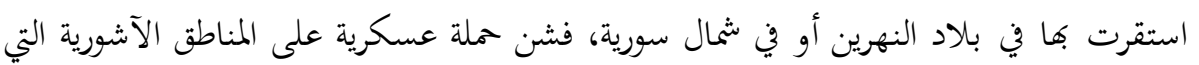

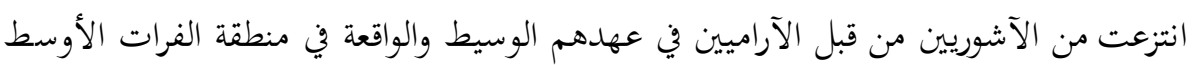

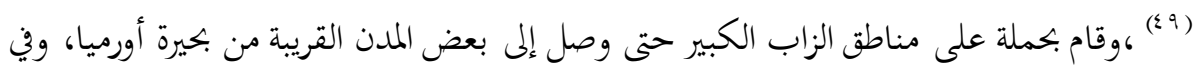

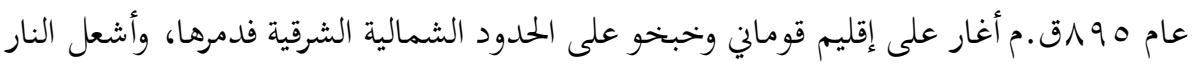

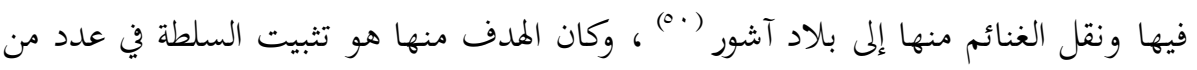
القلاع الآشورية في مدينة كومو أو قوماني، وبعد الاضطرابات التي حدثت استطاع التهاع أن يعيد إليها

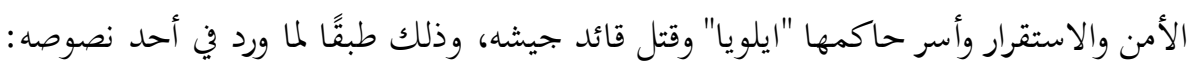
"بأمر إلهي وسيدى آشور زحفت لتقديم العون إلى قوماني، وقدمت القرابين للإله أدد في

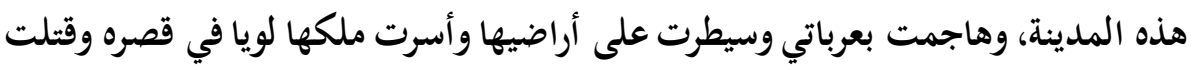

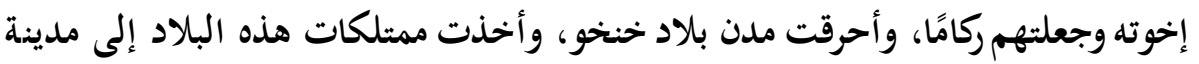

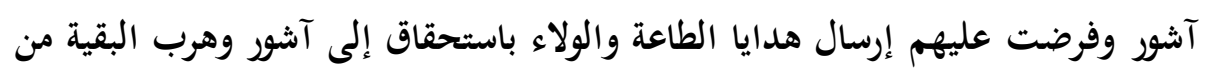
قبضتي" ( ) قام بحملة ثانية على إقليم قوماني وخبخو التي امتنعت عن دفع الجزية وإرسال

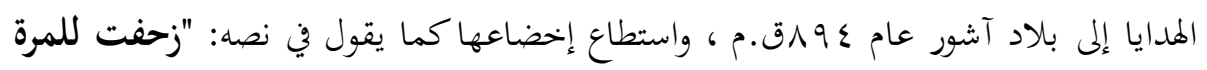
الثانية إلى إقليم قوماني وفتحت وأحرقت وحطمت مدن ساتكورو وياسادو كونو وتابسيا 
ومدن من بلاد خبخو عند أطراف قوماني التي امتنعت عن دفع الجزية"، كما هاجم إقليم

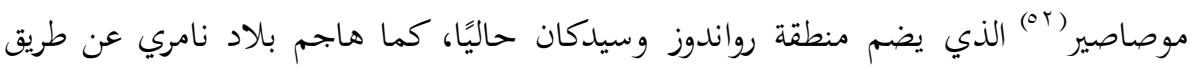

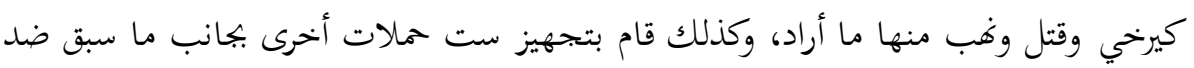

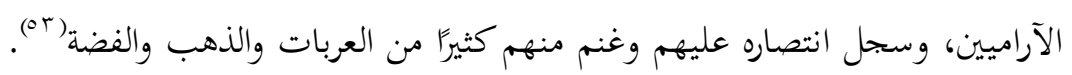

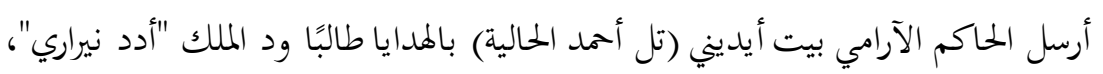

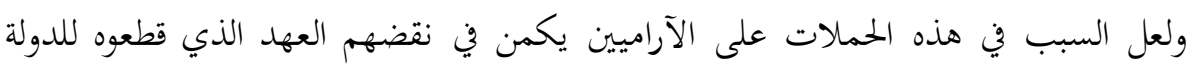

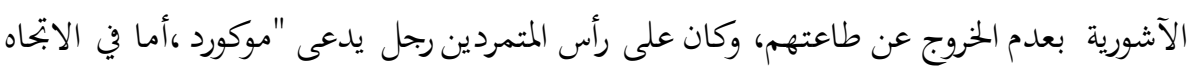

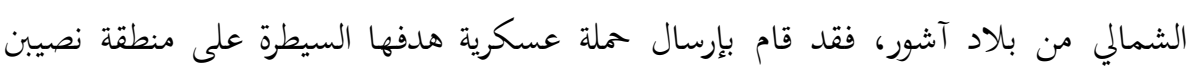

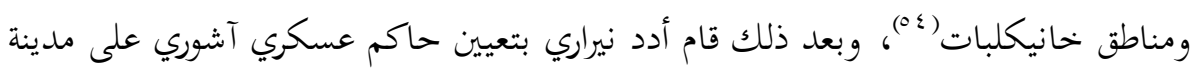

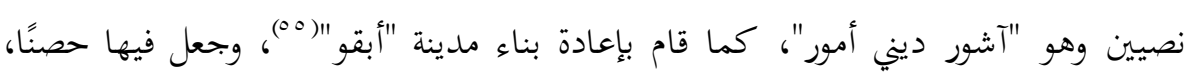

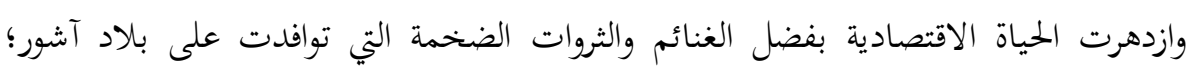

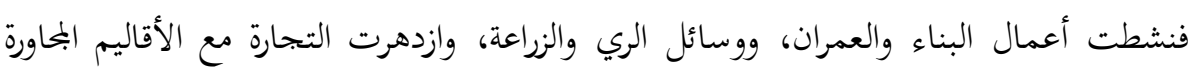
بفضل ما فرضه من أمن وسلامة على الطرق التجارية (†').

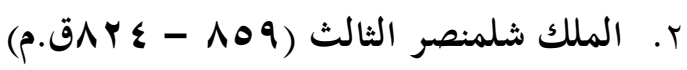

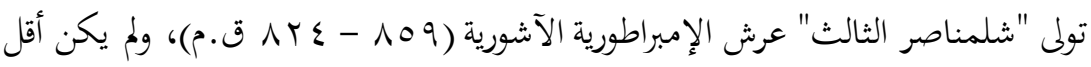

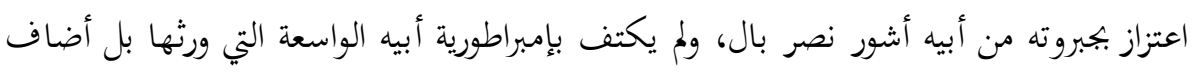

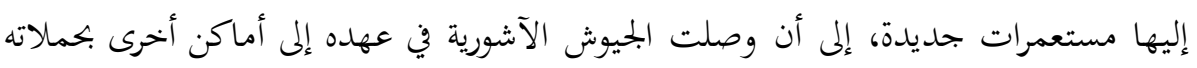

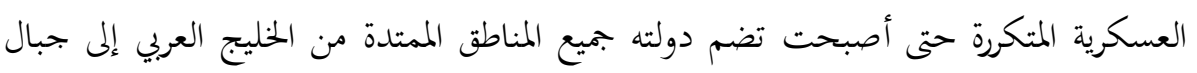

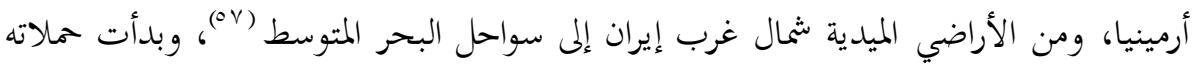

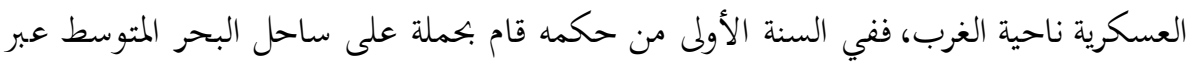

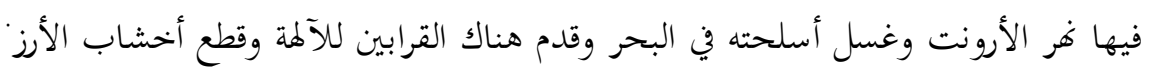

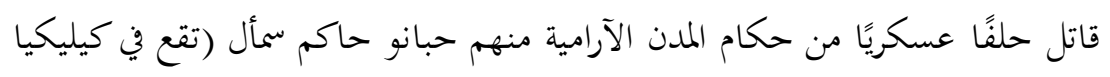

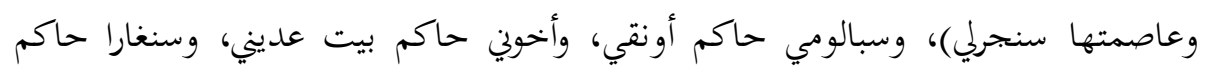

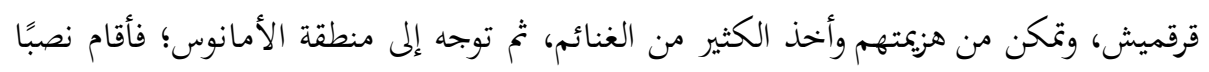

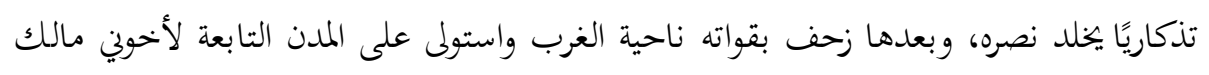

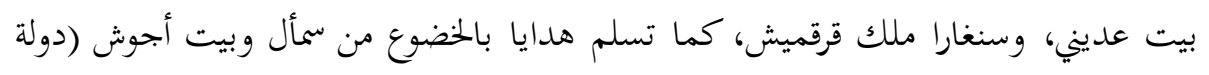

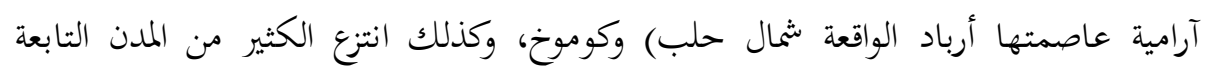


للآراميين ،وفي ظل تلك الانتصارات المتلاحقة للملك شلمنصر الثالث، فقد ساد أرامي سورية

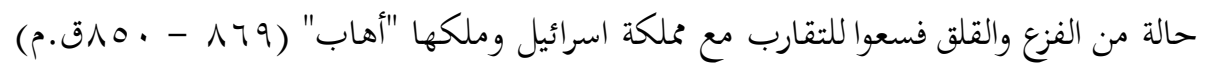

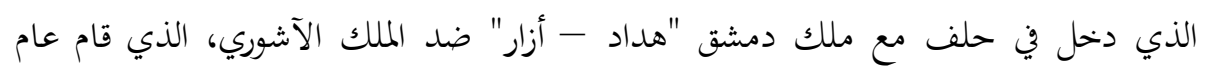

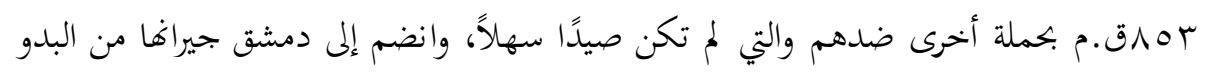

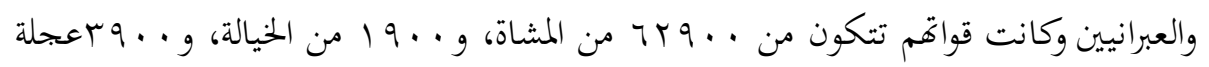

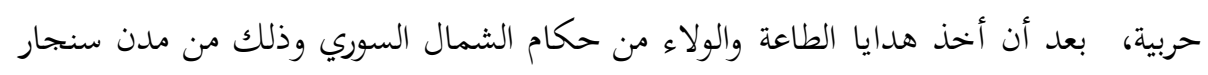

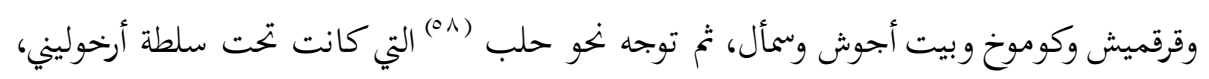

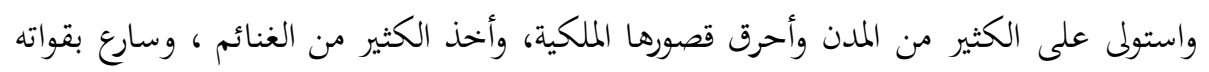

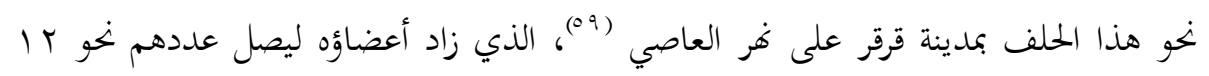

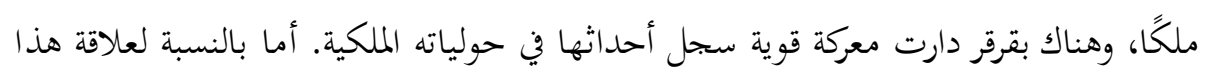

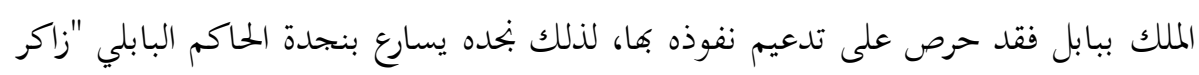

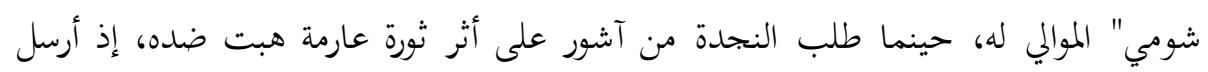

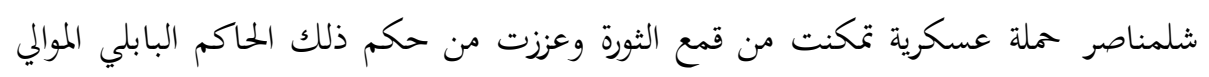
للآشوريين (·)، وانتهى حكم شلمنصر الثالث بثورة داخلية في بلاد آشور تزعمها أحد أبنائه

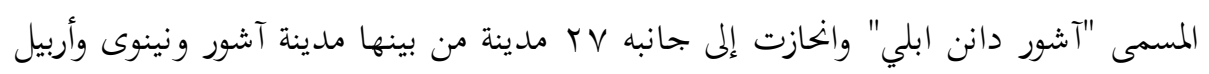

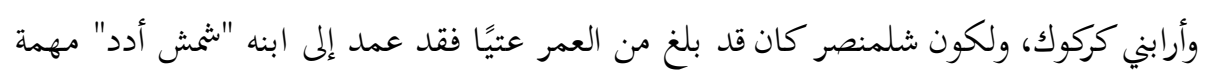

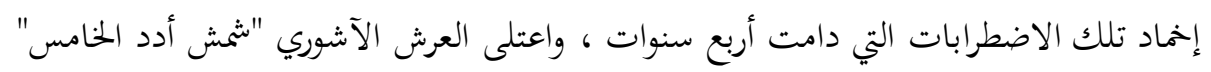

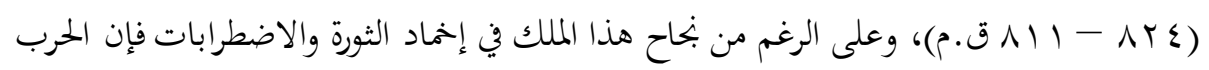

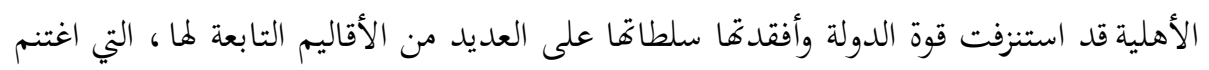

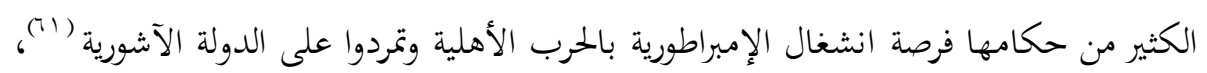

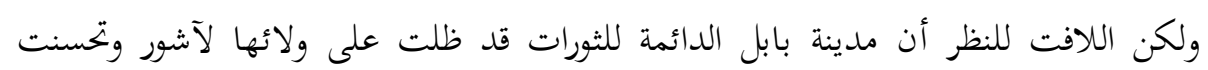

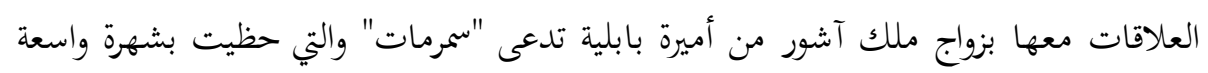

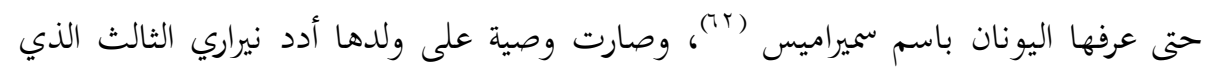
اعتلى العرش وهو صغير السن بعد وفاة والده.

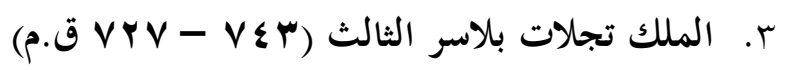

كان عهده من العهود الجحديدة في حياة الإمبراطورية الآشورية وتوفرت فيه قيادة جديدة تعيد للإمبراطورية مجدها السابق وتنفض الغبار عن كاهلها لذلك أعاد تنظيم الإدارة 
الآشورية وإصلاحها إصلاحا جذريًا؛ ليضمن سلامة وأمن الدولة، لذلك كان حكم الملك بتحلات

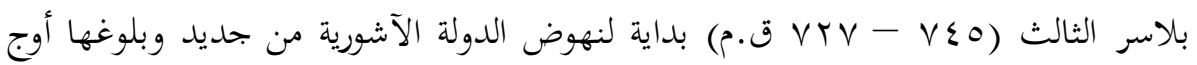

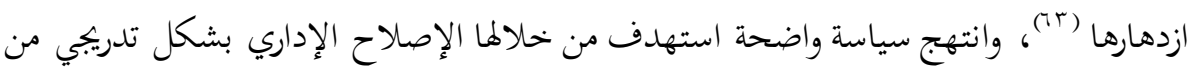

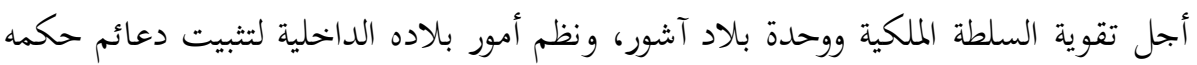

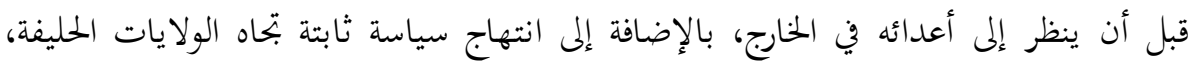

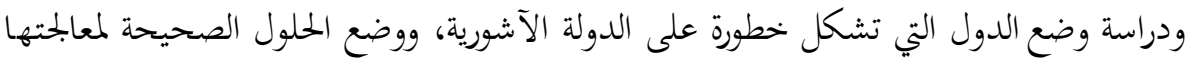

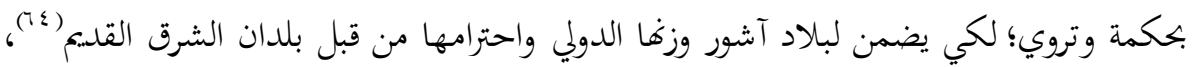

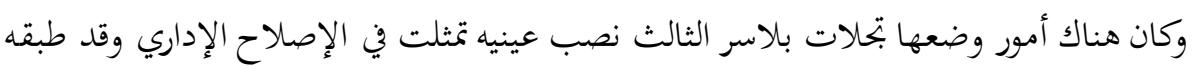

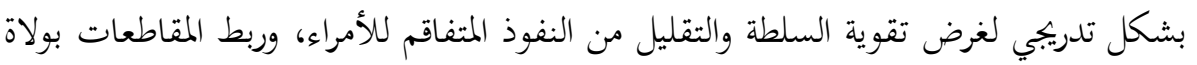

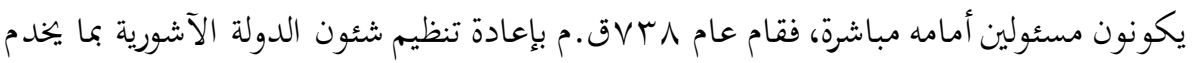
المصلحة العامة لذلك قام بمنح الأمراء من العائلة الملكية بعض المقاطعات الإدارية لإدارتا

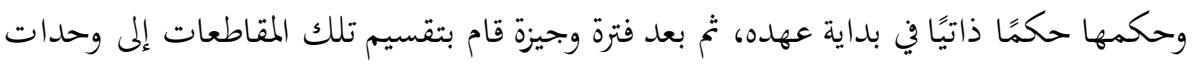

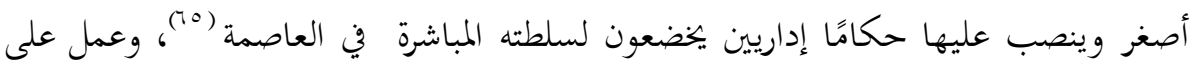
الربط بين مختلف المواقع والمقاطعات بالمواصلات؛ ليعزز من إحكام السيطرة على أطراف

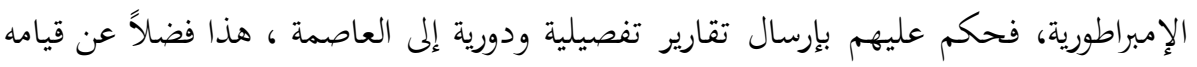

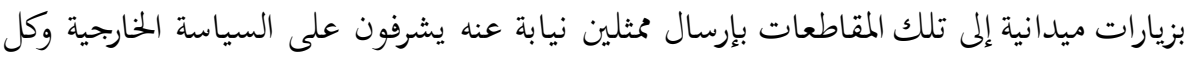

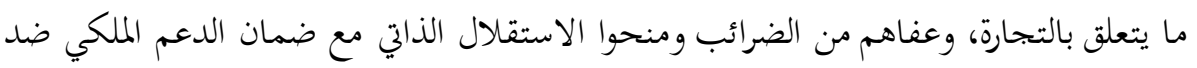

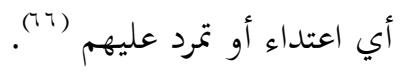
كان من أهم المشاكل التي واجهت الدولة الآشورية في عهد بتحلات بلاسر الثالث

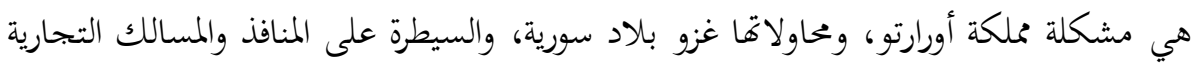

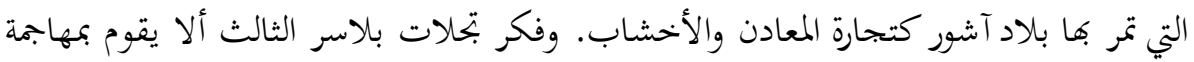

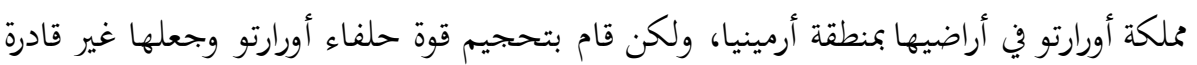

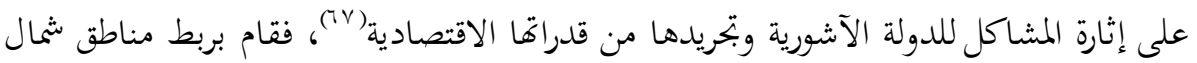

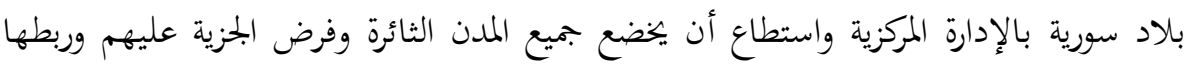
بالسلطة المركزية كما ذكرنا مثل: منطقة دهوك وزامو، وقام بترحيل شعوب هؤلاء المناطق إلى شمال

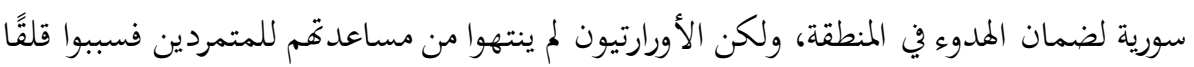

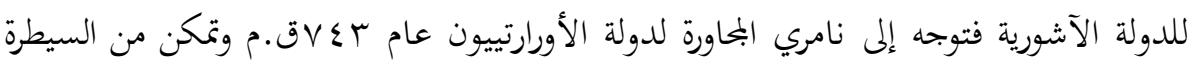


عليها دون مقاومة (1)"، ثم أخضع الأراضي في شرق دجلة من بلاد الأناضول وجنوبي بحيرة أورميا

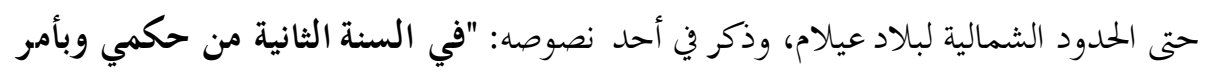
من الإله آشور سيدي الذي كان في عوني ضد أرض الذامري أوقفت تقدم الأورارتيين

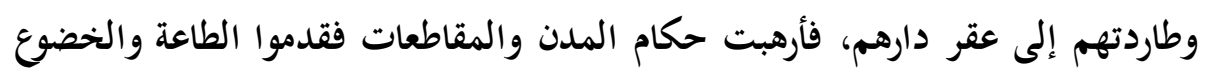

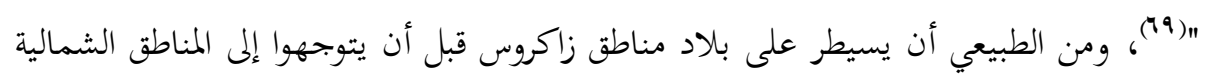

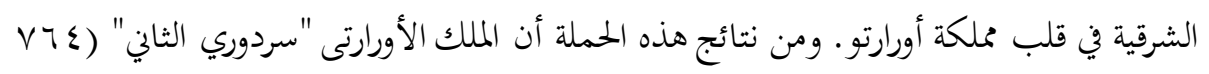

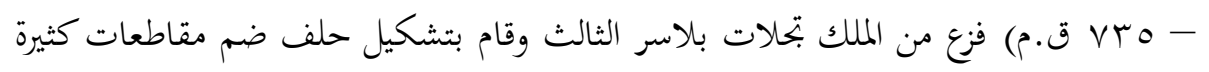

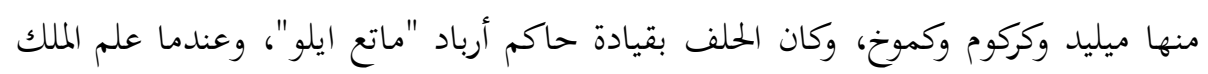

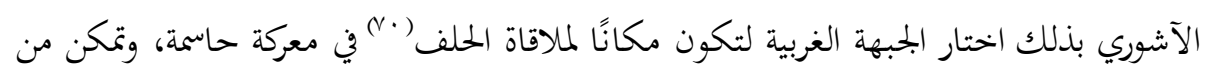

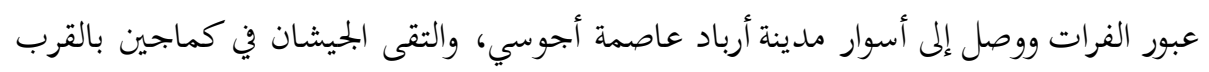

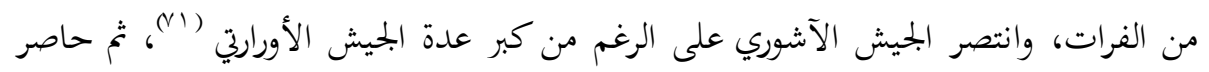

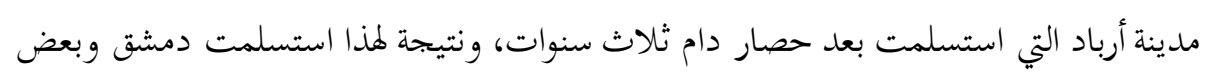

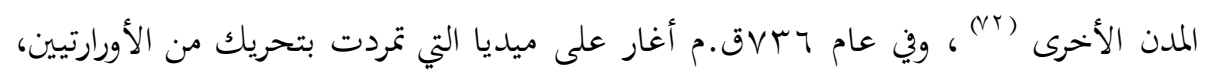

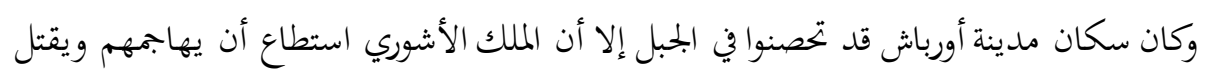

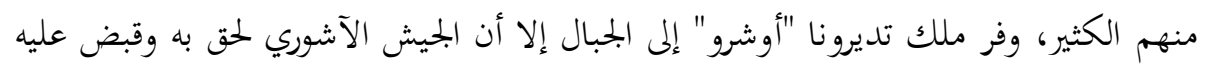

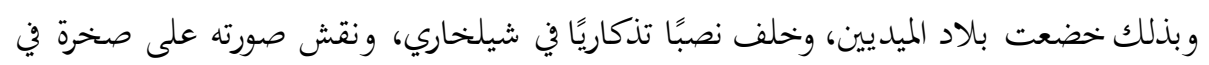

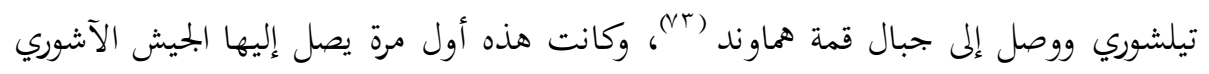

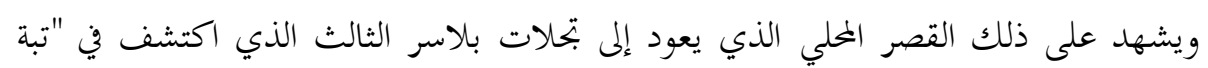

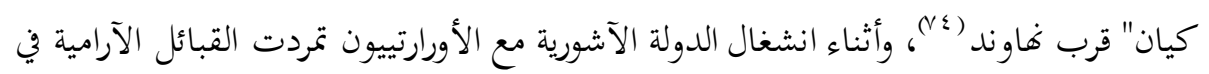

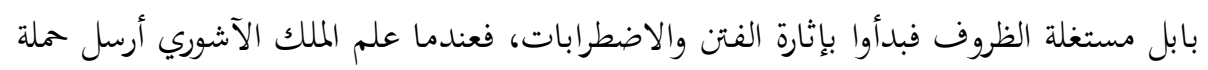

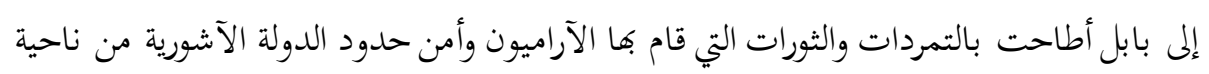

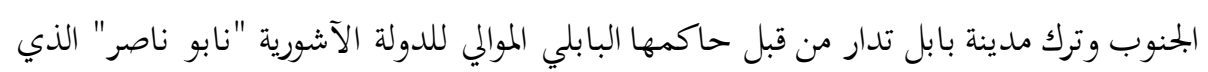

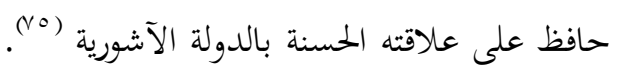




\section{ب- - المرحلة الثانية لأمبراطورية آشور الحديثة:

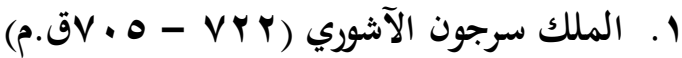

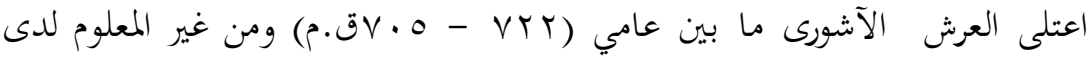
المؤرخين علاقته بالملك السابق شلمنصر الخامس بالنسبة لحكمه للدولة الآشورية من كونه أحد

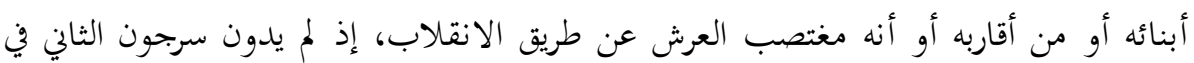

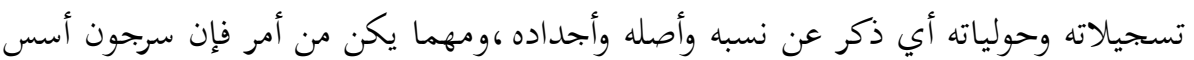

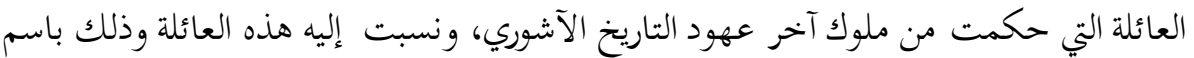

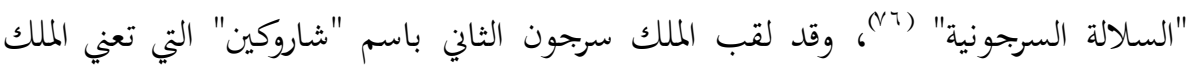
الحقيقي أو الصادق أو المسكين وهى تسمية مأخوذة من التوراة من سفر الملوك الثاني ، ،، وجهه

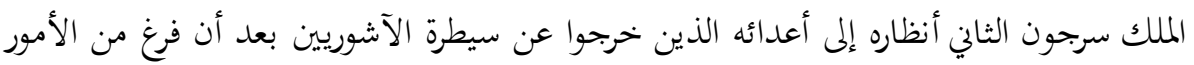
الداخلية للبلاد، وأثرت بشكل سلبي على تحارتا الدولية، فاستغلت بعض الأقاليم والمقاطعات

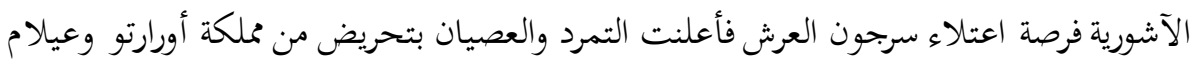

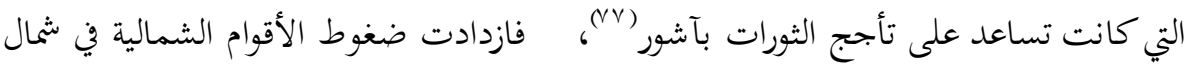

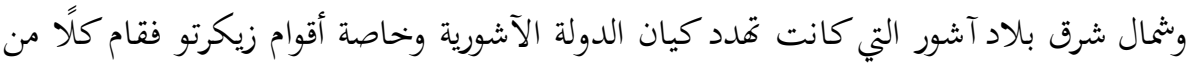

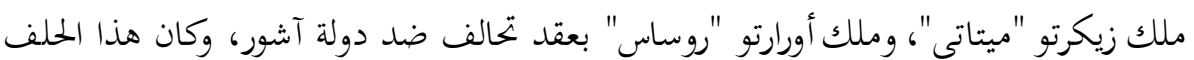

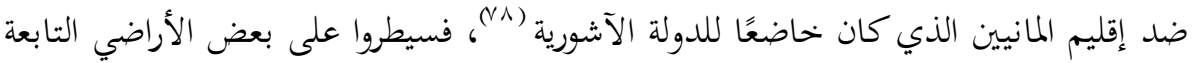

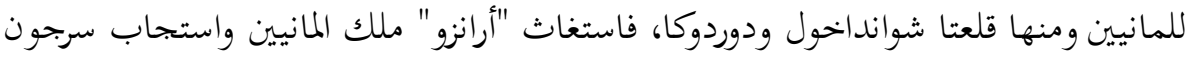

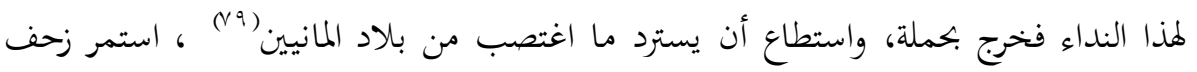

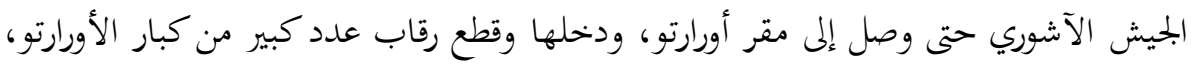

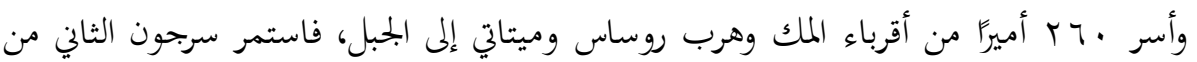
ملاحقة المنهزمين فاتحًا الكثير من المدن في طريقه إلى الشمال ودخل أورارتو من ناحية الشرق؛

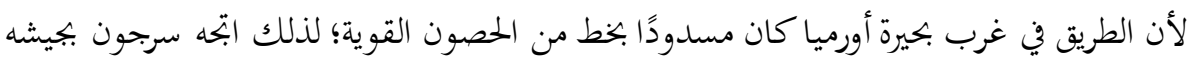

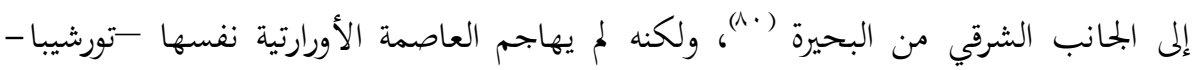

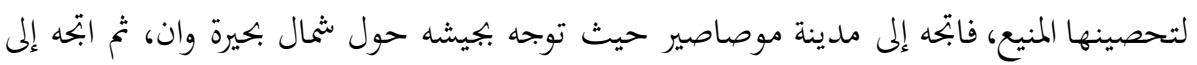

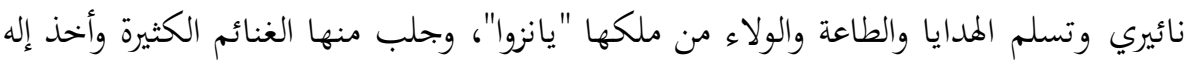

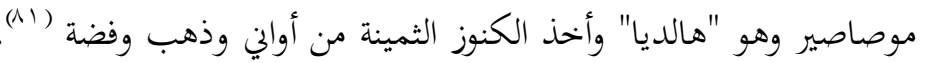




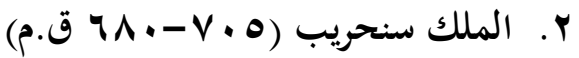

تولى عرش الإمبراطورية الآشورية الثانية الملك سنحريب بعد وفاة والدهات والده الملك سرجون

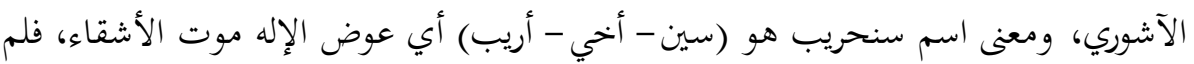

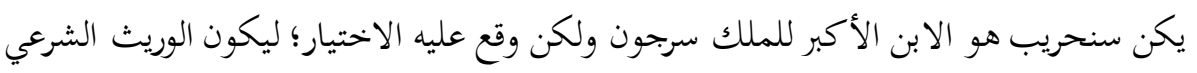
للملك سرجون، فقد تربى وتدرب في القصر الملكي، وأسندت إليه الكثير من المسؤوليات الإدارية

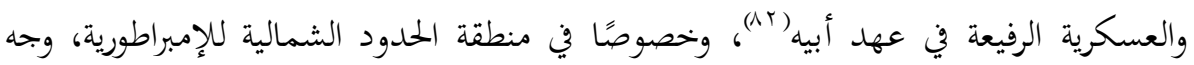

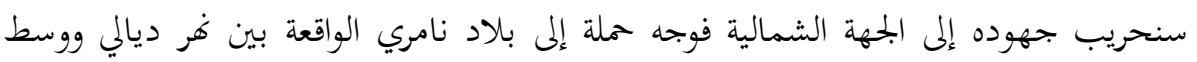

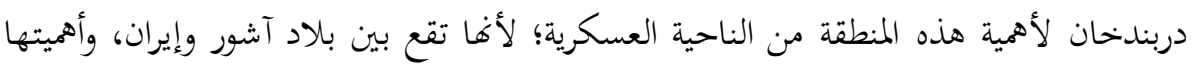

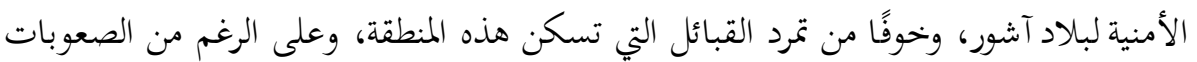

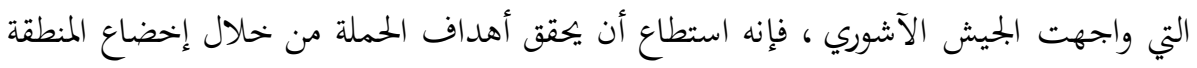

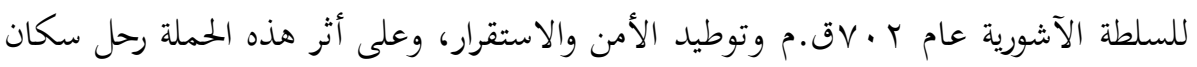

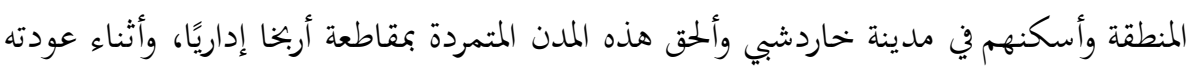

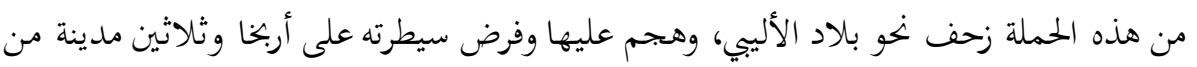

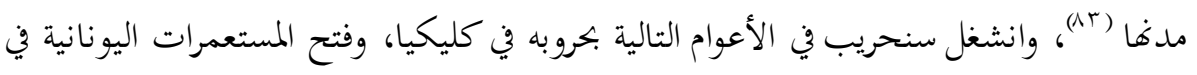

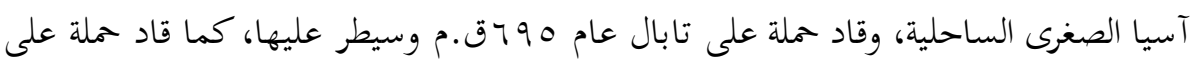

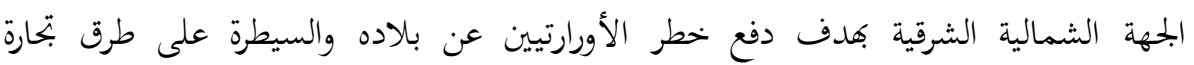
آشور

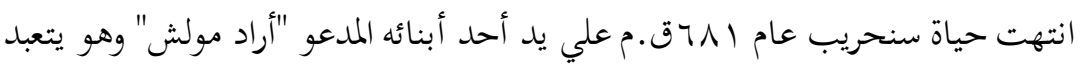

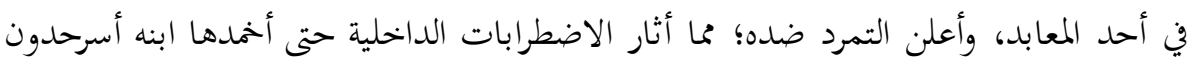
بعد ثلاثة أشهر (10).

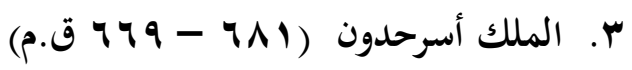

شهدت الجبهة الشمالية والشمالية الشرقية في بداية حكم أسرحدون تدفق أقوام هندو المارو

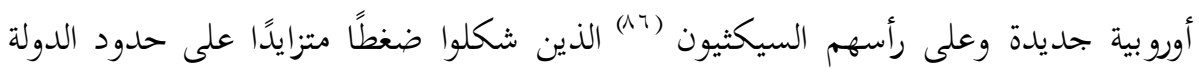
الآشورية، وألحقت هذه الأقوام بالكميريين الذين توغلوا في وقت قصير التيونيون في آسيا الصغرى وأرمينيا،

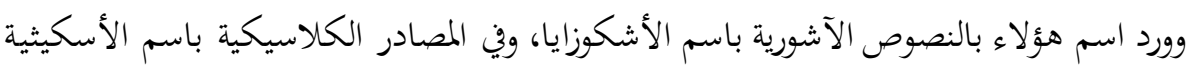

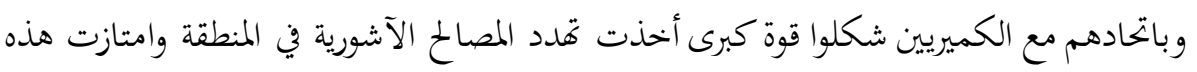

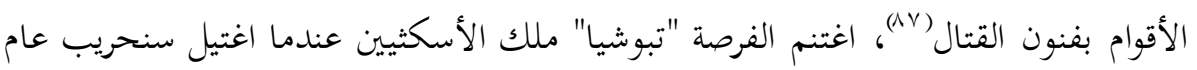


9 9דق.م ، وأغار على الحاميات الآشورية في خيلاكو، وكليكيا، وتابال، في آسيا الصغرى إلى الشمال الغربي من بلاد النهرين، فقام أسرحدون بشن حملة عليهم وتمكن من هزيمة ملكهي الكهم

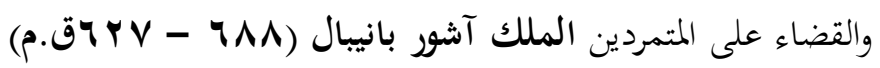
بدأ نفوذ الآشوريين يتقلص في المنطقة الشمالية والشمالية الشرقية نتيجة انشغال الجيش بهري

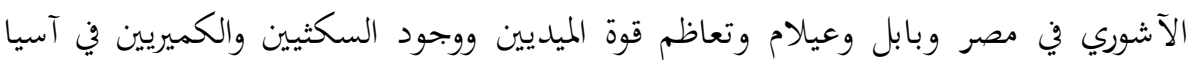

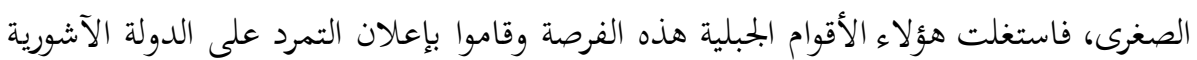

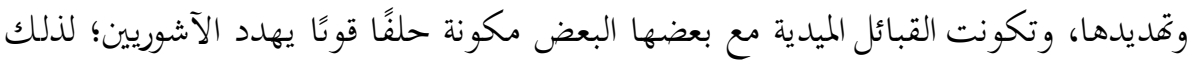

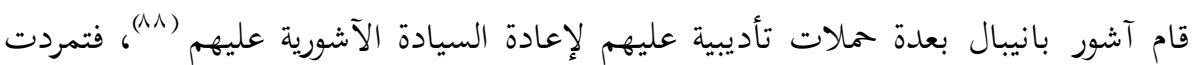

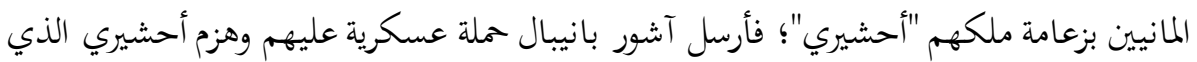

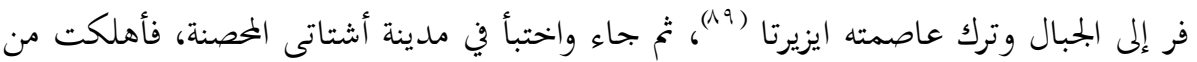
الحصار الذي فرضه عليهم آشور بانيبال، فقام جنود أحشيرى بقتله وألقوا جثثنه خارج المدينة

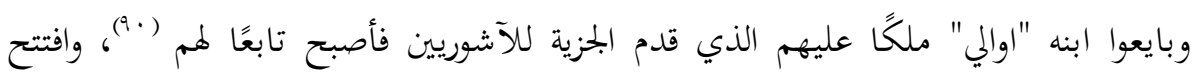

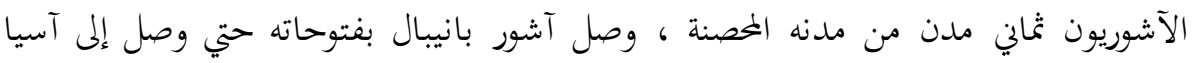

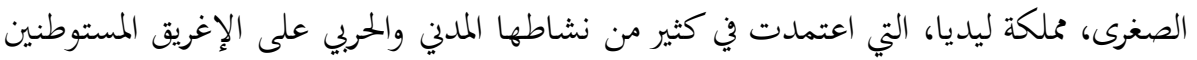

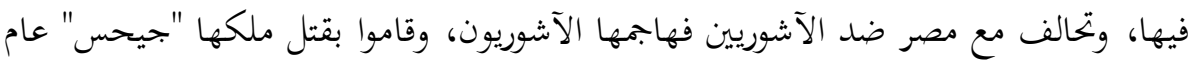

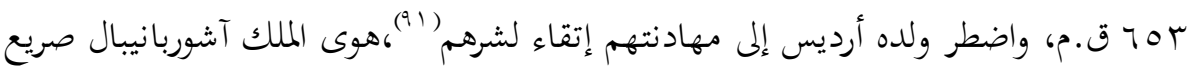

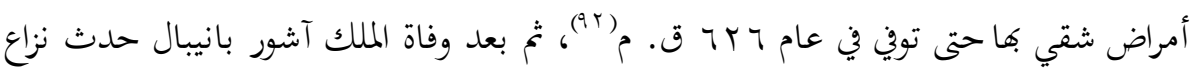

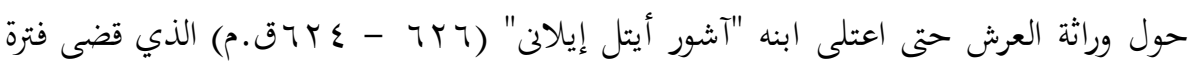

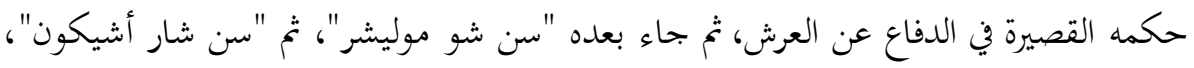

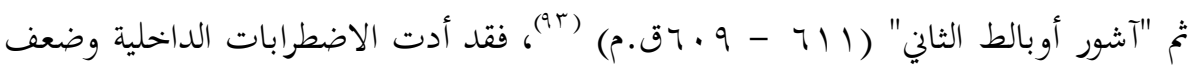

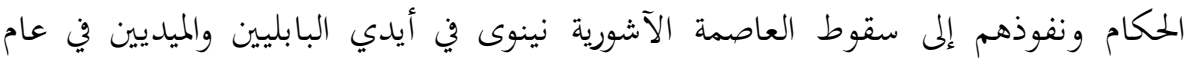
rابقق.م بعد معركة دموية أدت إلى سقوط الدولة الآشورية بسقوط العاصمة نينوى ودمروها

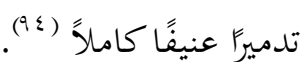




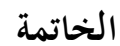

تمتعت مناطق الشرق الأدنى القديم وخصوصًا بلاد آشور طوال الألف الثالث قبل الميلاد؛

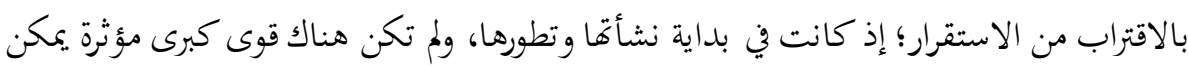

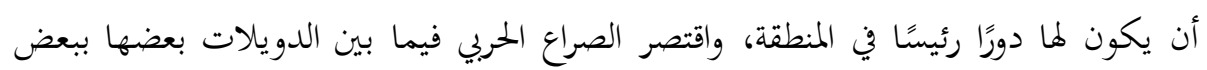

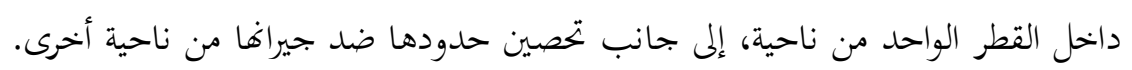

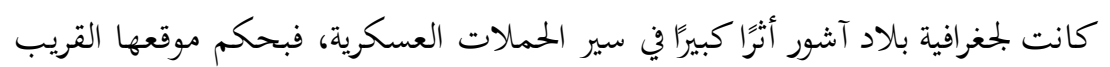

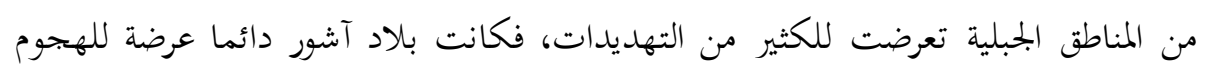

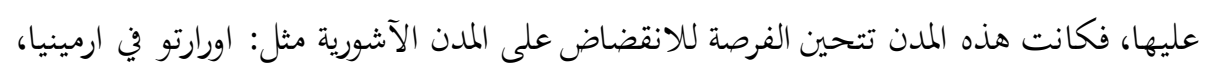

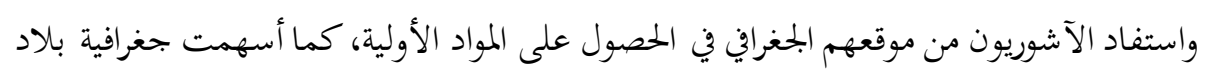

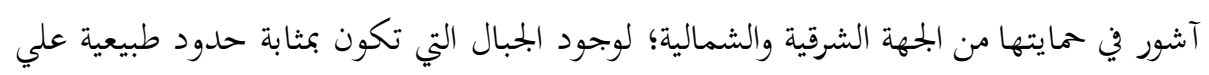
عكس الجنوب والغرب.

لم يشهد العصر الآشوري القديم حملات كثيرة على المناطق الشمالية والشمالية الشرقية؛

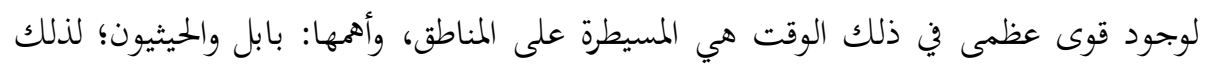
اقتصر نشاطها على العلاقات التجارية معًا. قامت الحملات العسكرية الآشورية؛ بهدف إعادة النظام وردع الخطر عن بلادهم، كما

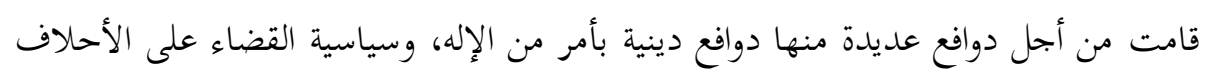

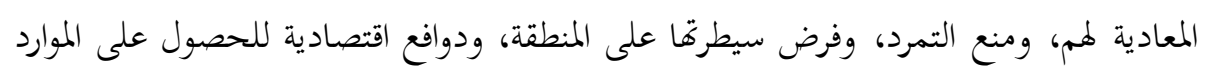
الأولية للحفاظ على بحارها والطرق التجارية الخاصة بها. 
أحمد أمين سليم: مدراسات فى تاريخ وحضارة العراق القديم، الاسكندرية، مكتبة المعرفة الجامعية،

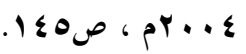

(") زيباري عزيز محمد أمين والشديفات يونس محمد: الحملات العسكرية الأشورية على المناطق الواقعة إلى الشمال والشمال الشرقي لبلاد أشور في ضوء النصوص المسمارية المنشورة، رسالة ماجيستير غير

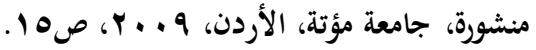

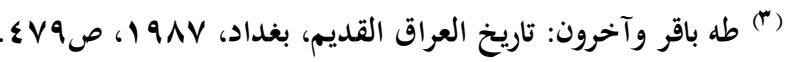

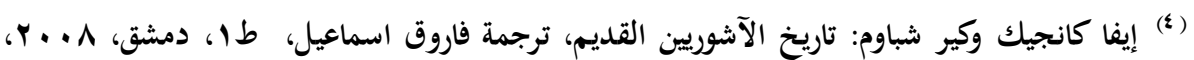

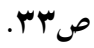

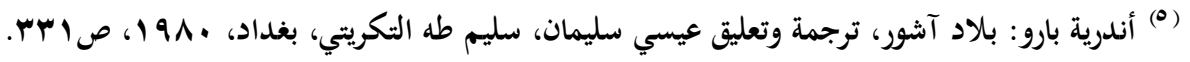

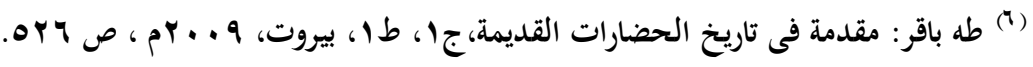
(v)

(8) Delaparte, L. Masopotamia, The Babylonia and Assyrian Civilization, London, 1925, p.18.

(9) توفيق سليمان: دراسات في حضارات غرب آسيا القديمة من أقدم العصور حتى •911 اق.م (الشرق

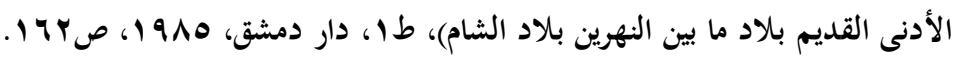

(•) تقع هذه المدينة على بعد هبكم إلى الشمال الشرقي لمدينة الديوانية، وكانت هذه المدينة في منتصف الألف الثالث قبل الميلاد مركزًا دينيًا وثقافيًا لبلاد سومر ، ونقب فيها العالم الإنجليزي ليارد عام

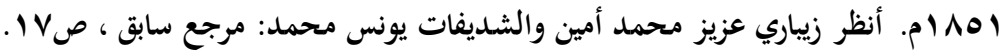
(1) - (') طه باقر وآخرون: مرجع سابق، صV9 ـ 
(r) فاضل عبد الواحد علي: السومريون والأكاديون في موسوعة العراق في التاريخ، بغداد، بهA I،

$$
\text { صYr). }
$$

(14) Mallowan, M. E. F. "The Bronze Head of Akkadian Period from Nineveh"' in, IRAQ, vol.. III, 1936, p. 104.

(10) تل الحريري حاليا يقع على بعد حوالي المم شمال غربي بلدة البو كمال عند الحدود العراقية السورية ، وعلى بعد ه, ك كم غربي نهر الفرات، واحتلت المدينة من قبل سرجون الأكادي في مساره نحو شمال سوريه، وكانت مدينة مهمة في عهد مملكة أور الثالثة. يُنظر:

Jacobsen, Th. The Sumerian King-List, 1939, p.22.

(ه) تذكر في بعض الأحيان بصيغة أقلاطوم وهى مدينة لا نعرف موقعها بالضبط ، وتقع في وادي دجلة، وكانت تابعة لمدينة أشنونا. يُنظر: جورج رو: العراق القديم، ترجمة حسين علوان حسين، طب، بغداد، rOA

${ }^{17}$ Kupper, J. R. "Northern Mespotmia and Syria" in, CAH, 1973, p.1.

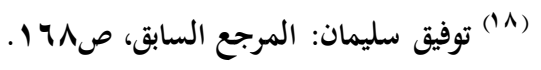

${ }^{19}$ Poeble, A. "The Assyrian King List from Khorsabad" in, JNES, 1, 1942, p.247.

${ }^{(20)}$ Leamans, W. F. "The old Babylonian Merchant", Leiden, 1950, p.78. 
(1) الحيثين هم من الأقوام الهندو أوروبية قدموا إلى منطقة وسط هضبة الأناضول عند منحى نهر الهاليس، وأطلقوا عليها اسم حاتي، ومنها عرفوا بالحاثيين، وعاصمتهم عرفت باسم حاتوثاش (بوغازي الحالية) التي تبعد مسافه •^ ميلاً شرق انقرة. يُنظر:

Gurney, O. R. "The Hittites", London, 1961, p.5.

(r) جرني: الحيثيون، ترجمة محمد عبد القادر محمد، بغداد، باج 9 (1، صع ع. (T) هم قبائل جبلية جاءت من الراي إلى شرق جبال زاجروس، ابتداء من الأسرة البابلية الأولى، واختلف المؤرخون حول أصلهم، وهل هم عناصر هندو أوروبية أم عيلامية. يُنظر: مشير الناضوري: مرجع سابق، صل آ؛ السيد محمد السعيد: مرجع سابق، ص•V.

( « هم الذين ذكرتهم النصوص المصرية باسم تاومتن واسم خاسوت من، وينحدرون من عناصر هندو أوروبية، اشتهروا باسم الميتانين، وكونوا طبقه من النبلاء المحاربين واتحدوا مع الحوريين من بني عمومهم، وهم الذين وفدوا إلى المنطقة قبلهم من منطقه القوقاز، وانتشروا في بلاد الأناضول، واتخذوا واشاكاني عاصمة لهم (تل الفخارية حاليًا). يُنظر : محمد علي سعدالله: دراسات في تاريخ الشرق الأدنى القديم -

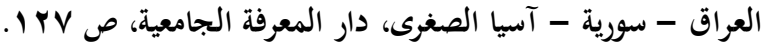

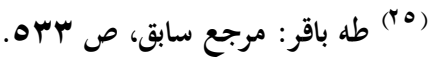

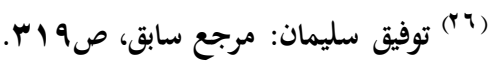

(VV) غيث حبيب خليل: العلاقات السياسية الآشورية في عهد الملك آشور أوبالط الأول

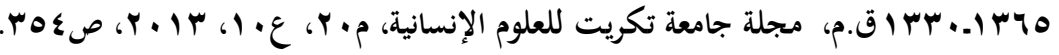

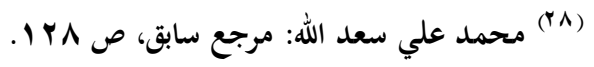

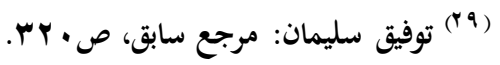

${ }^{(30)}$ Godd, C. J. Gadd, C. J. " Hammurabi and The End of Hisdynasty"' in CAH, vol.. II, part 1, p. 24 . 
( آم) هي عاصمة الفرعون المصري إخناتون تقع على الضفة الشرقية لنهر النيل ضمن محافظة المنيا فى مصر الوسطى مركز دير مواس على بعد • 9 ا كم جنوب القاهرة، وأطلق عليها اسم أخت آتون بمعنى أفق أتون، ووضع لوحات حدود على ضفتي النيل، ولكن المدينة هجرت بعد وفاة مؤسسها ، وقد عثر في هذه المدينة عام ANV ام مصادفة عن طريق إحدى الفلاحات على مجموعة من الرسائل الملكية الهامة جدًا والتي عرفت باسم رسائل تل العمارنة، وهى عبارة عن مجموعة من رسائل دبلوماسية متبادلة في عهد كل من إمنحوتب الثالث وولده إمنحوتب الرابع إخناتون. يُنظر: أحمد فخرى: تل العمارنة في الموسوعة

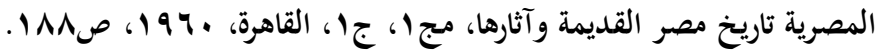

${ }^{32}$ Mum-Rankin, M. J. " Assyrian Military Power", in CAH, vol. II, p.274.

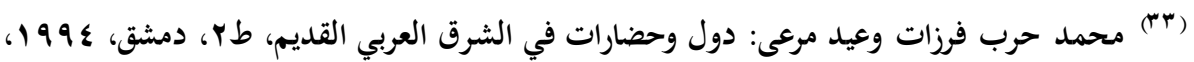
ص

${ }^{(34)}$ Mum-Rankin, M. J. op.cit., p. 275.

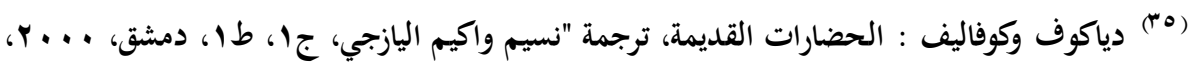
ص

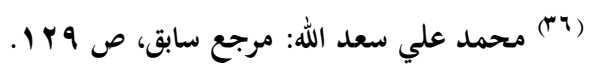

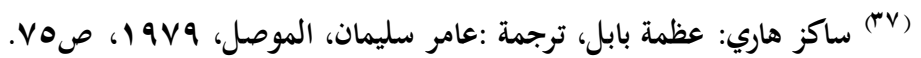

(38) Mum-Rankin, M. J. op.cit., p.280.

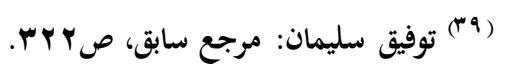

(•) تعرف بقاياها الآن بتلول العقر شمال آشور بنحو ميل واحد على الضفة اليسرى لنهر دجلة. يُنظر: عامر سليمان: العصر الآشوري في موسوعة العراق في التاريخ، بغداد، به9 ا، صץ I I.

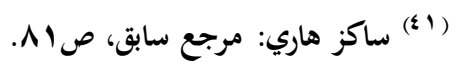




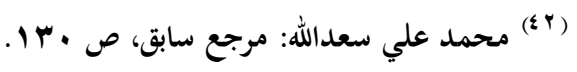

(َّا) دولة قوية في جنوب شرق آسيا الصغرى ورعاياها ينتمون إلى أقوام جبلية، كانوا يشكلون أحد الموجات الهندو أوروبية. يُنظر: ساكز هاري: مرجع سابق، صـ ـ ا. ( ؛ \&) زيباري عزيز محمد أمين والشديفات يونس محمد: مرجع سابق، ص اس.

(0) أمل ميخائيل بشور: تاريخ الإمبراطوريات السامية في بابل وآشور لبنان، م ـ. ب، ص •01.

$$
\text { ( ) جورج رو: المرجع السابق، صه • ع. }
$$

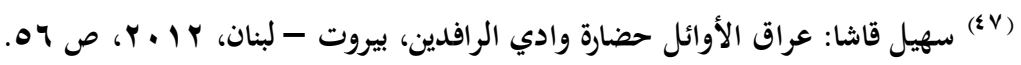

(^) أحمد مالك القتبان: نظام الحكم في العصر الآشوري الحديث، رسالة دكتوراة غير منشورة، جامعة

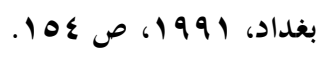

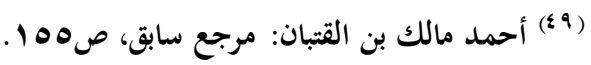

${ }^{50}$ Smith, S. M. A. " The Foundation of The Assyrian Empire", in C.A.H. vol. III, The Assyrian Empire ,Cambridge, 1965, p.7.

$$
\text { (1) (1) زيباري عزيز محمد أمين والشديفات يونس محمد: مرجع سابق، ص99. }
$$

(r) عاصمة إقليمية لمملكة أورارتو، وتقع في الزاوية الشمالية الشرقية لبلاد آشور، وهى مركز عبادة إله

$$
\text { الأورارتيين. يُنظر :المرجع نفسه، ص } 79 .
$$

${ }^{(53)}$ Smith, S. M. A. op.cit., p.9.

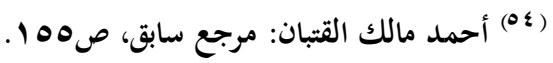

$$
\begin{aligned}
& \text { (ه) وهي تل ابي ماريا والتي تقع إلى الغرب من نينوى بحوالي هץ كم. يُنظر: }
\end{aligned}
$$

Smith, S. M. A. op.cit., p. 9. 
V) زيباري عزيز محمد أمين والشديفات يونس محمد: مرجع سابق، ص VI)

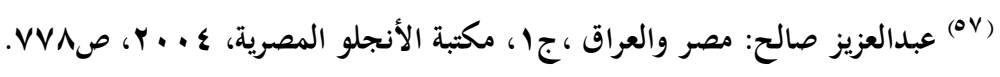

هن (OA)

${ }^{59}$ Smith, S. M. A. op.cit., p. 22.

$$
\begin{aligned}
& \text { ( •) أحمد مالك القتبان: مرجع سابق، صVVV . } \\
& \text { (") عبدالعزيز صالح: مرجع سابق، ص • ("). }
\end{aligned}
$$

(r) اختلفت روايات المؤرخين الإغريق فيما سمعوه عن هذه الفترة بقصة محورة لملكة أطلقوا عليها اسم سميراميس تحريفًا فيما يبدو للاسم الآشوري سمرمات أي محبوبة الحمام، وكانت وصية على ابنها أدد نيراري الثالث من زوجها شمش أدد الخامس، وارتبطت بها اسطورة تقول: بأن أم هذه الملكة كانت معبودة تعبد في عسقلان قرب سواحل البحر المتوسط ويرمز إليها بصورة نصفها سمكة ونصفها حمامة، ولما ولدت ابنتها على هيئة بشرية سوية تركتها للحمام يرعاها لهذا سميت بهذا الاسم، وبعد ذلك عثر عليها كبير رعاة ملك آشور فأخذها ورباها وعندما كبرت تزوجها حاكم نينوى أونيس، ولكن ملك آشور العظيم نينوس طمع فيها وأجبر زوجها على التخلي عنها وتركها، فكان هذا السبب في انتحاره فلجأت إلى حيلة لتنتقم لزوجها ولنفسها فتقربت لملك وطلبت منه أن يعهد إليها بالعرش والسلطة لمدة خمسة أيام لكى يرى كيف تحكم فقبل الملك، فاستغلت سلطانها المؤقت وأمرت بسجن الملك ثم قتله، واغنصبت العرش بعده أكثر من ·ـ عامًا. يُنظر: رمضان عبده علي: الشرق الادنى وحضاراته الى مجئ الاسكندر

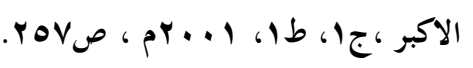

(بآ) محمد أبو المحاسن عصفور: معالم تاريخ الشرق الادنى القديم من أقدم العصور الى مجئ

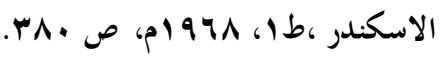

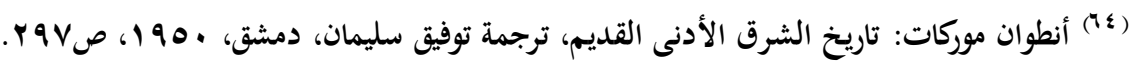
(0) طه باقر: مرجع سابق، ص • . 
(דان) عامر سليمان: العصر الاشورى فى موسوعة العراق فى التاريخ، بغداد، ب19 (م) ص 101.

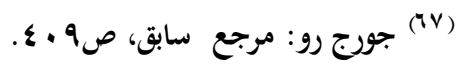

(1) زيباري عزيز محمد أمين والشديفات يونس محمد: مرجع سابق، ص. ․

(99) زيباري عزيز محمد أمين والشديفات يونس محمد: مرجع سابق، ص1 ـ 1.

${ }^{70}$ Saggs, H. W. F. " The Greatness That Was Babylon, New york, 1969, p. 105.

$$
\begin{aligned}
& \text { ( I) عامر سليمان: مرجع سابق، صبه } \\
& \text { (Nr) }
\end{aligned}
$$

(r) هي الجبال التي ورد ذكرها في المصادر الآشورية باسم بكيني. يُنظر: طه باقر: مرجع سابق، ص $.07 r$

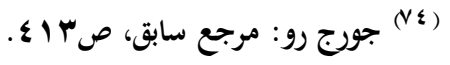

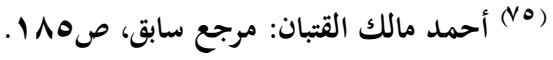

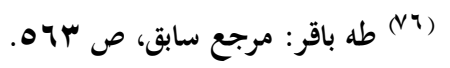

$$
\text { هنري ساغس: مرجع سابق، صب \& } 1 \text { (VV) }
$$

محمود الأمين: تعليقات تاريخية على حملة سرجون الثامنة، مجلة سومر، عه، جr، بغداد، (NA)

$$
\text { 9 }
$$

$$
\begin{aligned}
& \text { (N9) دياكوف. و. س. كوفاليف: مرجع سابق، صء r. }
\end{aligned}
$$

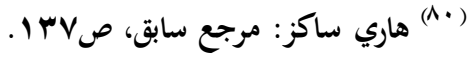


(81) Wright, E. "The Eight Campaign Sargon II of Assyria 714B.C. ", in JNES, vol. 2, 1943, p.173.

${ }^{82)}$ Lucknbill, D. D. "The Annals of Sennacherib" in, O.I.P, vol.. 11, Chicago, 1924, p.29.

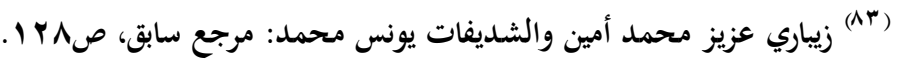

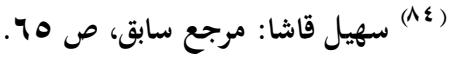

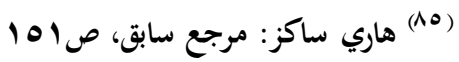

(ז) هم من القبائل الهندو أوروبية، ويروي هيرودوت أن الأسكيثين قد أزاحوا الكميريين، رغم أنهما كانوا متحدين وعاشوا على النهب والسلب، واستوطن السيكثيون حول أطراف بحيرة أورميا. يُنظر: طه باقر:

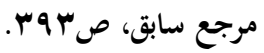

$$
\begin{aligned}
& \text { هاري ساكز : مرجع سابق، ص00) } \\
& \text { (^^) عامر سليمان: مرجع سابق، ص109. }
\end{aligned}
$$

${ }^{89}$ Saggs, H. op.cit., p. 109.

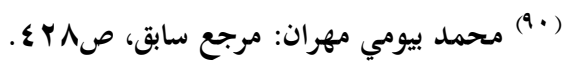

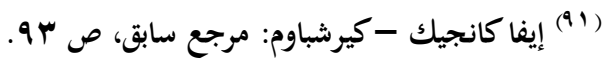

(9) علاء قابيل: مرجع سابق، ص 101.

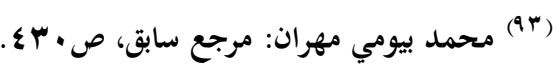

(\$) عبد العزيز صالح: مرجع سابق، صroه. 